\title{
Avaliação de ferramentas automáticas para a extração da rede de drenagem a partir de dados de elevação SRTM para o município de Paragominas, estado do Pará, Brasil \\ Evaluation of automatic tools for drainage network extraction from SRTM elevation data for Paragominas Municipality, Pará, Brazil
}

\author{
Jorge Luis Gavina Pereiral, ", Leandro Valle Ferreira", Gil Mendes Sales", \\ Marcelo Cordeiro Thalês"I, René Poccard-Chapuis"II, Camilo Daleles Rennó ${ }^{\mathrm{IV}}$, Sérgio Rosim ${ }^{\mathrm{IV}}$ \\ 'Rede Biodiversidade e Biotecnologia da Amazônia Legal. Programa de Pós-Graduação em \\ Biodiversidade e Biotecnologia. São Luís, Maranhão, Brasil \\ "Museu Paraense Emílio Goeldi/MCTIC. Belém, Pará, Brasil \\ IIICentre de Coopération Internationale en Recherche Agronomique pour le Développement. Paris, France \\ INInstituto Nacional de Pesquisas Espaciais. São José dos Campos, São Paulo, Brasil
}

\begin{abstract}
Resumo: A extração da drenagem utilizando dados de elevação representa etapa importante em diversos estudos ambientais. A topografia é usualmente manipulada nos Sistemas de Informações Geográficas (SIG), na forma de um Modelo Digital de Elevação (MDE). Na década de 1980, foi consolidado método para extração da drenagem a partir do MDE, baseado em correção de depressões, definição da direção de fluxo, cálculo de acúmulo de fluxo e extração da drenagem. Os valores de elevações podem representar a altura do terreno ou das árvores. A correção do MDE para altura do terreno melhora a extração da drenagem. O objetivo deste trabalho é avaliar o resultado da extração da drenagem pelas ferramentas Arc Hydro e TerraHidro, utilizando MDE da Shuttle Radar Topography Mission (SRTM), submetido à filtragem e a diferentes correções de altura de dossel florestal. Foram utilizadas drenagens de cartas topográficas para avaliar os resultados. Das drenagens extraídas pelo Arc Hydro, a que utilizou o dado com correção de dossel 3, sem filtragem, foi a que apresentou a menor diferença com relação às cartas topográficas $(283 \mathrm{~m})$. ○ TerraHidro obteve a drenagem com a menor diferença em relação às cartas topográficas $(270 \mathrm{~m})$ a partir do dado com correção de dossel 2, filtrado.
\end{abstract}

Palavras-chave: Recursos hídricos. Modelo Digital de Elevação. Direções de escoamento. Acumulação de fluxo. Arc Hydro. TerraHidro.

\begin{abstract}
Drainage extraction using elevation data represents an important step in several environmental studies. Topography is usually manipulated in Geographic Information Systems (GIS) in Digital Elevation Model (DEM) format. In the 1980s, a method was established for drainage extraction from DEM, based on depressions correction, flow direction definition, flow accumulation calculation, and drainage extraction. Elevation values can represent terrain height or tree height. DEM correction for ground height improves drainage extraction. The objective of this paper is to evaluate drainage extraction by Arc Hydro and TerraHidro hydrological tools using SRTM DEMs subjected to filtering and different forest canopy height corrections. Topographic drainage maps were used to evaluate the results. Among of drainages extracted by the Arc Hydro which presented the smallest difference in relation to the topographic maps $(283 \mathrm{~m})$. data were used with canopy correction 3, without filtering. TerraHidro obtained the drainage with the smallest difference in relation to topographic maps $(270 \mathrm{~m})$ by using filtered data with canopy correction 2 .
\end{abstract}

Keywords: Water resources. Digital Elevation Model. Flow direction. Flow Accumulation. Arc Hydro. TerraHidro.

PEREIRA, J. L. G., L. V. FERREIRA, G. M. SALES, M. C. THALÊS, R. POCCARD-CHAPUIS, C. D. RENNÓ \& S. ROSIM, 2018. Avaliação de ferramentas automáticas para a extração da rede de drenagem a partir de dados de elevação SRTM para o município de Paragominas, estado do Pará, Brasil. Boletim do Museu Paraense Emílio Goeldi. Ciências Naturais 13(3): 409-433.

Autor para correspondência: Jorge Luis Gavina Pereira. Museu Paraense Emílio Goeldi/MCTIC. Coordenação de Ciências da Terra e Ecologia. Av. Perimetral, 1901 - Terra Firme. Belém, PA, Brasil. CEP 66077-530 (jorgegavina@museu-goeldi.br).

Recebido em 21/12/2017

Aprovado em 12/08/2018

Responsabilidade editorial: Fernando da Silva Carvalho Filho

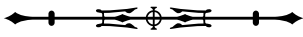




\section{INTRODUÇÃO}

A drenagem de uma região depende, entre outros fatores, da pluviosidade, da topografia, da cobertura vegetal, do tipo de solo, da litologia e da estrutura das rochas (Suguio \& Bigarella, 1990). A extração da rede de drenagem a partir de dados de elevação, realizada por meio de Sistemas de Informações Geográficas (SIG), representa uma importante etapa em diversos estudos ambientais, tais como em análises hidrológicas sobre riscos de erosão e de inundações e sobre produção de sedimentos. Muitos desses estudos fazem uso de parâmetros derivados da rede de drenagem, como a densidade de drenagem, o comprimento e a quantidade de cursos d'água, a relação de bifurcação e a confluência, o perfil longitudinal etc. (Morais \& Sales, 2016).

Todos os principais SIG, sejam eles comerciais, como ArcGIS Desktop (ESRI, 2010) e TerrSet - que incorporou o IDRISI (Clark Labs, 2018) -, ou de livre acesso, como Geographic Resources Analysis Support System (GRASS) (GRASS Development Team, 2018), System for Automated Geoscientific Analyses (SAGA) (Conrad et al., 2015) e Quantum Geographic Information System (QGIS) (QGIS Development Team, 2018), possuem ferramentas automáticas para a extração de drenagem e para a delimitação de bacias hidrográficas. Existem, ainda, programas para análises hidrológicas que podem ser utilizados como extensões (plug-ins) de SIG, como Terrain Analysis Using Digital Elevation Models (TauDEM) (Tarboton et al., 2015), o qual se pode utilizar como uma extensão do ArcGIS Desktop, e a ferramenta desenvolvida pelo Instituto de Pesquisas Hidráulicas (IPH), da Universidade Federal do Rio Grande do Sul (UFRGS), chamada de IPH-Hydro Tools (Siqueira et al., 2016), como uma extensão do MapWindow (Ames et al., 2018). Alguns programas, como o TauDEM e o TerraHidro - versão 5 (INPE, 2016), podem também ser executados diretamente do console do sistema operacional Windows, por meio de comandos de linha.

Os dados topográficos são usualmente manipulados nos SIG sob a forma de um Modelo Digital de Elevação
(MDE), que possui estrutura matricial (raster), onde cada elemento ou célula (pixel) tem como atributo o valor de elevação do terreno (Burrough \& McDonnel, 1998; Buarque et al., 2009). Atualmente, existem duas bases de dados de elevação em escala global de acesso livre: dados Shuttle Radar Topography Mission (SRTM), derivados da Missão Topográfica por Radar Orbital (Farr et al., 2007); e dados Advanced Spaceborne Thermal Emission and Reflection Radiometer - Global Digital Elevation Model (ASTER GDEM), gerados a partir de imagens do sensor ASTER, do satélite Terra (Abrams et al., 2010). Tanto os dados SRTM quanto os ASTER GDEM possuem resolução horizontal de $30 \mathrm{~m}$ e vertical de $1 \mathrm{~m}$. De acordo com Morais \& Sales (2016), os MDE derivados de sensoriamento remoto têm sido a principal fonte de dados de elevação da superfície terrestre utilizada na caracterização e na modelagem hidrológica de bacias hidrográficas.

Dependendo da forma como o MDE foi gerado, as elevações podem representar a superfície do terreno (altura do chão) ou da cobertura da terra, que correspondem à altura do dossel das árvores em áreas de florestas (Oliveira et al., 2014). Como os modelos de elevação correspondentes à superfície da cobertura da terra estão muito mais disponíveis (SRTM e ASTER GDEM), é desejável identificar problemas na geração de redes de drenagem usando esses dados. Em áreas extensas, o topo das árvores pode ser uma representação aceitável do relevo. No entanto, os desflorestamentos, a presença de muitas árvores emergentes, de estradas, bem como mudanças súbitas no tipo de vegetação introduzem artefatos nos dados de elevação, levando a uma extração incorreta da rede de drenagem. $\bigcirc$ uso de imagens classificadas com a identificação de desmatamento e de regiões florestais melhora a extração da drenagem (Oliveira et al., 2014).

Rennó (2009) propõe a correção dos dados SRTM (MDE), subtraindo-se um valor constante de todas as células pertencentes às áreas de floresta, o que corresponderia à retirada da floresta, fazendo com que a superfície do MDE se aproximasse da superfície real, supostamente encontrada

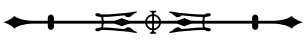


em áreas desmatadas (altura do chão). Através da avaliação do MDE resultante, Rennó (2009) verificou que os valores de elevação relativos às áreas de floresta deveriam ser subtraídos em $11 \mathrm{~m}$. Os resultados obtidos indicaram grande melhoria do MDE após a correção no que diz respeito à extração de rede de drenagem e a outros atributos do terreno, como a declividade.

Os primeiros esforços para extração automática de elementos e/ou de características geomorfológicas datam de meados da década de 1970, a partir da criação da matriz de elevação, elaborada com a utilização de cartas topográficas (curvas de nível e pontos cotados), quando se formulavam algoritmos para a identificação automática de elementos da paisagem e de dados morfométricos (Peucker \& Douglas, 1975). Na década de 1980, a preocupação voltou-se para a delimitação da bacia hidrográfica e para a extração da drenagem (Souza, J. \& Almeida, 2014). O'Callaghan \& Mark (1984) consolidaram um método para estudos hidrológicos a partir de um MDE cujos princípios são seguidos até hoje. Ainda que os algoritmos atuais tenham algumas modificações, eles seguem basicamente a sequência de passos proposta por O'Callaghan \& Mark (1984): correção de depressões, definição da direção de fluxo, cálculo de acúmulo de fluxo, extração da drenagem e delimitação da bacia (Souza, J. \& Almeida, 2014).

As depressões existentes em um MDE, bem como as células com valores de elevação inferiores aos dos seus oito vizinhos adjacentes (Mark, 1984; Wang \& Liu, 2006) interferem no escoamento superficial, precisando, portanto, ser devidamente corrigidas para que haja a obtenção de um modelo digital de elevação hidrologicamente consistente (Morais \& Sales, 2016), antes da geração dos parâmetros hidrológicos ora mencionados: direção de fluxo, cálculo de acúmulo de fluxo, delimitação da bacia e extração da drenagem (O'Callaghan \& Mark, 1984; Jenson \& Domingue, 1988; Poggio \& Soille, 2011).

Um método simples de remover depressões é feito através de um filtro de suavização. A operação de suavização é eficaz especialmente para remover as depressões mais rasas. Entertanto, quando aplicada indiscriminadamente, pode causar perda de informações significativas em áreas não problemáticas do MDE (Mark, 1984; O’Callaghan \& Mark, 1984; Wang \& Liu, 2006). Os métodos para a remoção de depressões podem ser categorizados, de forma geral, em incrementais, baseados no aumento dos valores de elevação das áreas de depressão (Jenson \& Domingue, 1988; Rosim et al., 2013), e decrementais, nos quais são diminuídos os valores de células vizinhas às depressões (Jones, 2002; Rosim et al., 2013).

O algoritmo para correção de depressões que está implementado no Arc Hydro, conjunto de ferramentas para análises hidrológicas desenvolvido para ser acessado através do ArcGIS (ESRI, 2011), utiliza a sequência de passos proposta por Jenson \& Domingue (1988). Ele elimina as depressões, aumentando a elevação das células dessas depressões até que elas atinjam o valor de elevação da borda, denominado de 'ponto de vazamento', conseguindo, desta forma, um caminho para o escoamento da água (Buarque et al., 2009; Huang \& Lee, 2015).

O TerraHidro, um sistema para modelagem hidrológica distribuída (Rosim et al., 2013; INPE, 2016), utiliza duas abordagens para resolver o problema das depressões. Na primeira, a elevação da depressão de uma única célula é substituída pela média da elevação dos seus oito vizinhos (Figuras $1 \mathrm{~A}$ a $1 \mathrm{C}$ ). Caso a depressão permaneça ou gere uma nova depressão em uma das suas células vizinhas, o seu valor não é substituído pela média dos seus vizinhos (Figuras 1D a 1F). Nestes casos, o TerraHidro utiliza, para eliminar a depressão, o algoritmo descrito por Jones (2002), centrado na busca da maior prioridade (Priority-First Search - PFS), elaborado com base em Sedgewick (1992). De acordo com Rosim et al. (2013), os dados SRTM possuem áreas planas espúrias nos grandes corpos d'água. $\bigcirc$ TerraHidro reconhece e delimita essas áreas, pois elas são escavadas. A drenagem flui no centro da área plana que foi escavada. Este procedimento é necessário porque o método PFS não produz bons resultados nas áreas planas (Rosim et al., 2013).

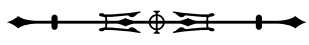


O algoritmo PFS está dividido em dois estágios. No primeiro, o PFS procura o melhor caminho que direcione o fluxo para fora da região de depressão. Esse caminho é denominado de 'caminho do fluxo', e as células dele são parte de um 'conjunto do caminho do fluxo' (Jones, 2002; Buarque et al., 2009; Rosim et al., 2013). No segundo estágio, os valores das células ao longo do caminho do fluxo são ajustados para que elas formem um caminho com valores decrescentes de elevação. A célula inicial é a primeira célula de depressão escolhida no primeiro estágio. A célula final é a que tem um valor menor do que a depressão ao longo do caminho do fluxo, ou a célula localizada no limite do MDE. O PFS ajusta os valores do MDE apenas ao longo de linhas com um pixel de largura e preserva as feições topográficas bem definidas dentro das depressões (Jones, 2002).

Em Rosim et al. (2013), é apresentado esquematicamente o método de remoção de depressões, utilizando o algoritmo PFS, que está implementado no TerraHidro. O primeiro passo é a identificação de uma depressão que não pode ser removida por um preenchimento simples, como é o caso da célula destacada em vermelho na Figura 2A (valor 3,0). $O$ segundo passo é a identificação da célula de saída do fluxo, a célula destacada em verde na Figura 2B (valor 2,8), e a definição do caminho que o fluxo percorrerá para chegar até esta célula (Figura 2B). Por fim, os valores das células ao longo do caminho do fluxo são diminuídos, formando um caminho com valores decrescentes da célula da depressão até a célula de saída (Figura 2B).

De acordo com Jenson \& Domingue (1988), após a correção das depressões, o segundo procedimento do método proposto por O'Callaghan \& Mark (1984) é a elaboração do conjunto de dados de direção do fluxo. Existem muitos métodos de definição das direções de escoamento com base em modelos digitais de elevação. A maior parte desses métodos define, para uma dada célula, uma única direção de fluxo (célula vizinha) que o escoamento deverá seguir (O'Callaghan \& Mark, 1984;

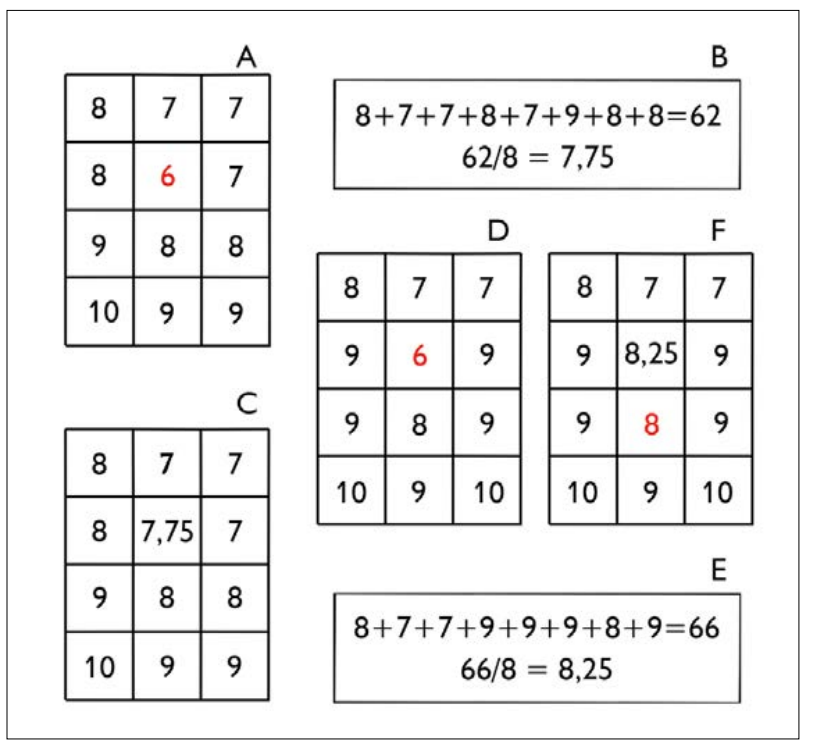

Figura 1. A) Depressão de célula única; B) média dos oito vizinhos da depressão; C) depressão eliminada utilizando a média dos oito vizinhos; D) depressão de célula única; E) média dos oito vizinhos da depressão; F) média gerando nova depressão (solução não utilizada). Fonte: modificado de Rosim et al. (2013).

\begin{tabular}{|c|c|c|c|c|c|c|c|c|}
\hline 4,0 & 3,4 & 3,5 & 4,0 & $A$ & 4,0 & 3,4 & 3,5 & 4,0 \\
\hline 3,5 & 3,0 & 3,2 & 3,5 & & 3,5 & 3,0 & 3,2 & 3,5 \\
\hline 4,0 & 3,1 & 3,6 & 3,6 & & 4,0 & 2,94 & 3,6 & 3,6 \\
\hline 5,0 & 3,2 & 3,3 & 2,8 & & 5,0 & 3,2 & 2,88 & $-2,8$ \\
\hline 5,0 & 4,0 & 3,5 & 3,4 & & 5,0 & 4,0 & 3,5 & 3,4 \\
\hline
\end{tabular}

Figura 2. A) Identificação inicial de uma depressão; B) caminho encontrado pelo método PFS. Fonte: Rosim et al. (2013).

Jenson \& Domingue, 1988; Buarque et al., 2009; Rosim et al., 2013). Outro grupo de métodos permite a partição do escoamento de uma determinada célula para mais de uma célula vizinha, ou seja, permite múltiplas direções de fluxo (Quinn et al., 1991; Tarboton, 1997; Seibert \& McGlynn, 2007).

Nos métodos que trabalham com uma única direção de fluxo, a determinação deste fator ocorre 
pelo critério do maior declive (Mark, 1984; O'Callaghan \& Mark, 1984). O declive da célula para os seus vizinhos nas direções cardeais ( $N, S, E$ e $O$ ) é definido como o valor da elevação da célula menos o valor da elevação do seu vizinho (Figura 3A). Para os vizinhos nas direções colaterais (NE, SE, NO e SO), o valor do declive deve ser dividido pela raiz quadrada de 2 (Figura 3A) (Siqueira et al., 2016). Os declives (descidas) ocorrem quando o valor da diferença é positivo. Os valores negativos representam subidas (aclives), e zero indica a ocorrência de mesma elevação (plano). Rosim et al. (2013) demonstram como, a partir do MDE (Figura 3B), são calculados os declives para uma determinada célula (Figura 3C), por meio dos quais a direção de fluxo desta célula é determinada. No exemplo de Rosim et al. (2013), o fluxo da célula $X$ foi para a direção $E$ (declive 3,0 ), indicada pela flecha vermelha (Figura 3C). Caso a maior declividade seja negativa, uma depressão singular é identificada na célula central (Siqueira et al., 2016).

A direção única de fluxo é o princípio básico dos algoritmos denominados de 'oito direções' (D8), sendo o método mais popular para extração automática de redes de drenagem e de bacias hidrográficas (Jones, 2002). Jenson \& Domingue (1988) propuseram uma codificação para as direções de fluxo em potência de 2 $\left(2^{x}\right)$, onde o expoente da potência $(x)$ recebe valores de 0 a 7, representando os oito vizinhos mais próximos da célula. Dessa forma, as codificações de direções de fluxo recebem os seguintes valores: 1, 2, 4, 8, 16, 32, 64 e 128. A partir do dado inicial de elevação (Figura 4A), define-se a direção única de fluxo pelo princípio do maior declive (Figura 4B), codificando-se as células com valores de 1 a 128 (Figura 4C), gerando-se a matriz de direções de fluxo (Figura 4D), onde está representada a direção de fluxo de cada célula. São exemplos de algoritmos D8 os algoritmos implementados no Arc Hydro (ESRI, 2011) e no TerraHidrro (Rosim et al., 2013).

De acordo com Jenson \& Domingue (1988), o terceiro procedimento do método proposto por

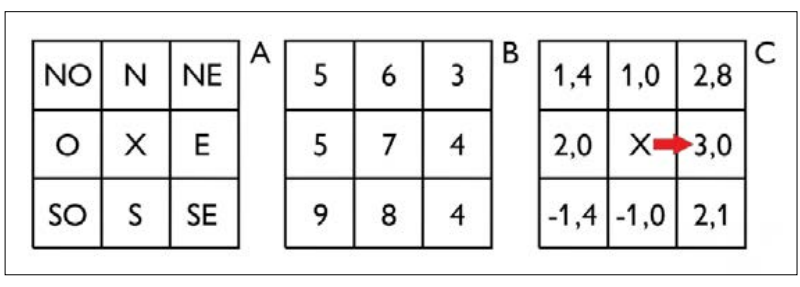

Figura 3. A) Direções cardeais e colaterais; B) valores de elevação (MDE); C) valores de declive e direção de fluxo. Fonte: Rosim et al. (2013).

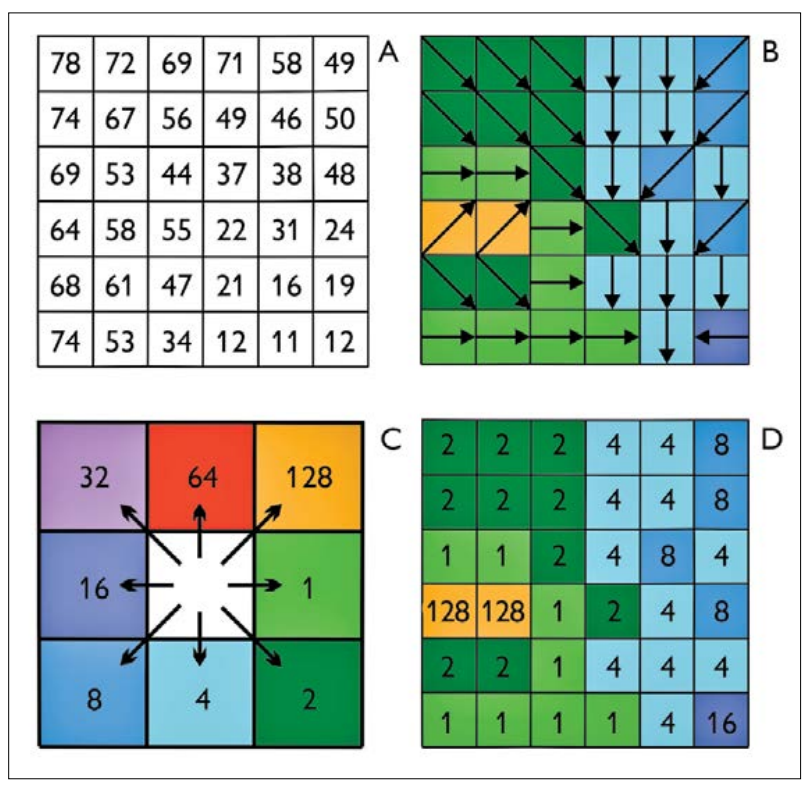

Figura 4. A) Dados de elevação; B) direção única de fluxo; C) codificação; D) direção de fluxo codificada. Fontes: ESRI (2017a) (A, C e D) e ESRI (2017b) (B).

O'Callaghan \& Mark (1984) faz uso da matriz de direção do fluxo para criar a matriz de acumulação dele. Inicialmente, cada célula pode ser considerada como produtora de uma quantidade unitária de escoamento, o qual é, então, levado para baixo, de acordo com as direções de drenagem (fluxo) das células da grade (Mark, 1984). Dessa forma, cada célula recebe um valor de escoamento igual ao número de células que fluem para ela (Figura 5A). O fato de as células terem valor de acumulação de fluxo igual a 1 significa que nenhuma outra célula flui para elas, o que geralmente corresponde ao padrão dos divisores de drenagem (Jenson \& Domingue, 1988).

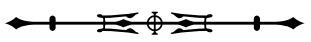


A partir da matriz de acumulação de fluxo, a rede de drenagem é gerada, sendo delimitada a bacia hidrográfica, que é uma informação gerada sem muita dificuldade, por ser composta por todas as células que drenam em direção a um mesmo ponto (Figura 5A). Por outro lado, a definição da rede de drenagem é uma tarefa um pouco mais complexa. Se a concentração espacial do escoamento superficial for simulada (dados de acumulação de fluxo), os pontos em que esse escoamento ultrapassar um determinado limiar (volume de água captada) podem ser considerados como parte da rede de drenagem (Mark, 1984; O'Callaghan \& Mark, 1984; Jones, 2002; Barták, 2009), como no caso da Figura 5B, onde, a partir do limiar de acúmulo de fluxo igual ou superior a 4, as células (destacadas em azul claro) são consideradas como parte da rede de drenagem (Rosim et al., 2014).

A rede de drenagem matricial pode ser convertida para o formato vetorial, a qual pode, assim, ser obtida em forma de linhas (Jenson \& Domingue, 1988). A partir da rede de drenagem em formato de linhas, muitos outros parâmetros podem ser derivados, como densidade de drenagem, comprimento e quantidade de cursos d'água, relação de bifurcação e confluência, perfil longitudinal, entre outros (Morais \& Sales, 2016).

Neste trabalho, propõe-se avaliar o resultado da extração da rede de drenagem pelas ferramentas Arc Hydro e TerraHidro para o município de Paragominas, utilizando-se MDE SRTM, submetidos a filtragem e a diferentes correções de altura de dossel florestal.

\section{MATERIAIS E MÉTODOS}

\section{ÁREA DE ESTUDO}

No escopo do Projeto TerraCert, que vem desenvolvendo uma proposta inovadora para a sustentabilidade na Amazônia através da certificação da trajetória dos territórios nos municípios de Paragominas e de Redenção, ambos no estado do Pará (Pacheco et al., 2017), a rede de drenagem e as bacias hidrográficas, extraídas pelas ferramentas de análises hidrológicas a partir do MDE SRTM, serão utilizadas como fonte de informação adicional nas análises de estrutura da paisagem do município de Paragominas, totalmente situado na Área de Endemismo Belém (AEB), que, por ter apresentado, em 2012, apenas 21\% de cobertura florestal original remanescente, foi classificada como estando em situação crítica por Braz et al. (2016). Devido a esta situação de elevada alteração da cobertura florestal original, os estudos de paisagem visam fornecer subsídios a iniciativas de conservação ambiental em Paragominas (Figura 6).

Os dados SRTM são disponibilizados pelo Serviço Geológico dos Estados Unidos (United States Geological Survey - USGS) através da internet (USGS, 2018). Os dados SRTM estão organizados em recortes de $1^{\circ}$ por $1^{\circ}$, com resolução espacial de $0,000278^{\circ}$ (30,91 m), Datum WGS-84 e coordenadas geodésicas (longitude/latitude). Eles encontram-se no formato GeoTIFF 16-bit, inteiro com sinal. Ou seja, em teoria, poderiam assumir valores inteiros entre -32767 e 32767, no qual o valor digital representa, em metros, o valor de elevação da célula (pixel), ou seja, a altitude geométrica (h), isto é, a altitude em relação ao elipsoide de referência WGS-84.

Para cobrir todo o município de Paragominas, incluindo uma região de entorno com $10 \mathrm{~km}$, são necessários seis recortes (imagens) SRTM: 1) s03_w047_larc_v3.tif; 2) s04_w047_1arc_v3.tif; 3) s03_w048_1arc_v3.tif; 4) s04_w048_1arc_v3.tif; 5) s03_w049_1arc_v3.tif; e 6) s04_w049_larc_v3.tif.

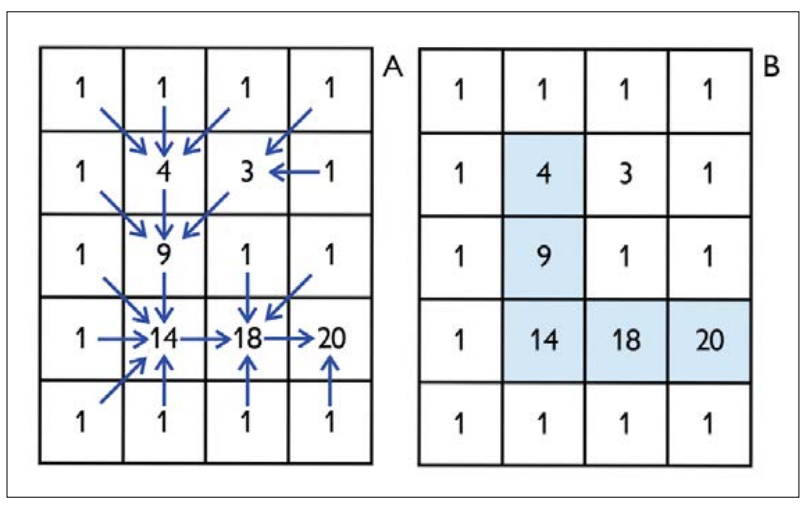

Figura 5. A) Fluxo acumulado; B) drenagem (limiar $\geq 4$ ). Fonte: Rosim et al. (2014).

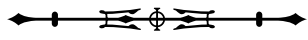



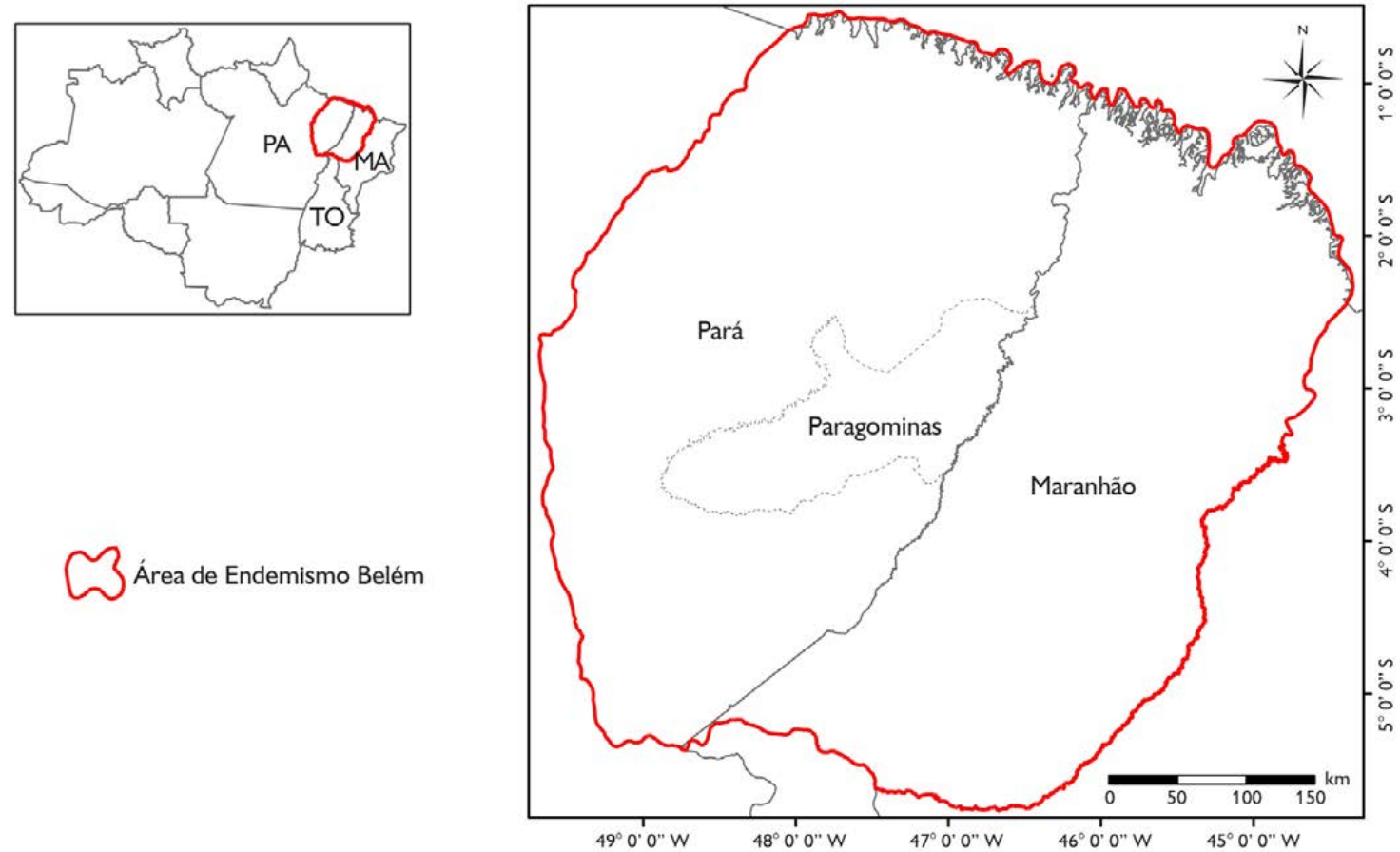

Figura 6. Localização do município de Paragominas.

Os dados SRTM foram manipulados no ArcGIS, onde foram convertidos para o formato ESRI GRID (matricial), unidos em um único arquivo, recortado para a área de interesse. Os valores de elevação SRTM para a área de estudo variaram de -13 a 248 m (Figura 7).

\section{CLASSIFICAÇÃO DE USO/COBERTURA DA TERRA}

Para minimizar o efeito do dossel da floresta nos dados SRTM (Rennó, 2009; Oliveira, et al., 2014), gerou-se uma informação de uso/cobertura da terra para o município de Paragominas a partir da classificação de imagens Landsat com datas próximas ao levantamento dos dados SRTM (anos de 1999 e 2000). Além da data, a escolha das imagens baseou-se na menor cobertura de nuvens. Na Tabela 1, são encontradas as imagens utilizadas na geração de informações de uso/cobertura da terra. As imagens Landsat também são disponibilizadas pelo USGS, através da internet(USGS, 2018).
Na elaboração do dado de uso/cobertura da terra, foi utilizado o Sistema de Informação Geográfica (SIG) denominado de Sistema de Processamento de Informações Georreferenciadas (SPRING) versão 5.5.1 (Câmara et al., 1996; INPE, 2017). Por se tratarem de registros feitos na mesma data, as imagens Landsat 5 223/62 e 223/63 (0506-2000), bem como Landsat 7 222/62 e 222/63 (07-081999) foram unidas, o que gerou dois conjuntos de imagens - Landsat 5 223/62-63 (05-06-2000) e Landsat 7 222/6263 (07-08-1999) -, classificados de forma independente. $\mathrm{Na}$ classificação desses dois conjuntos, foi utilizado um procedimento supervisionado por regiões, utilizando-se o algoritmo Battacharya, como descrito em Pereira et al. (2012). Após isso, as diversas classes resultantes dos dois conjuntos de imagens foram mapeadas para as seguintes categorias temáticas: - corpos d'água; - agropecuária; floresta secundária; - floresta degradada; - floresta madura; - nuvem e sombra.

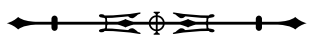




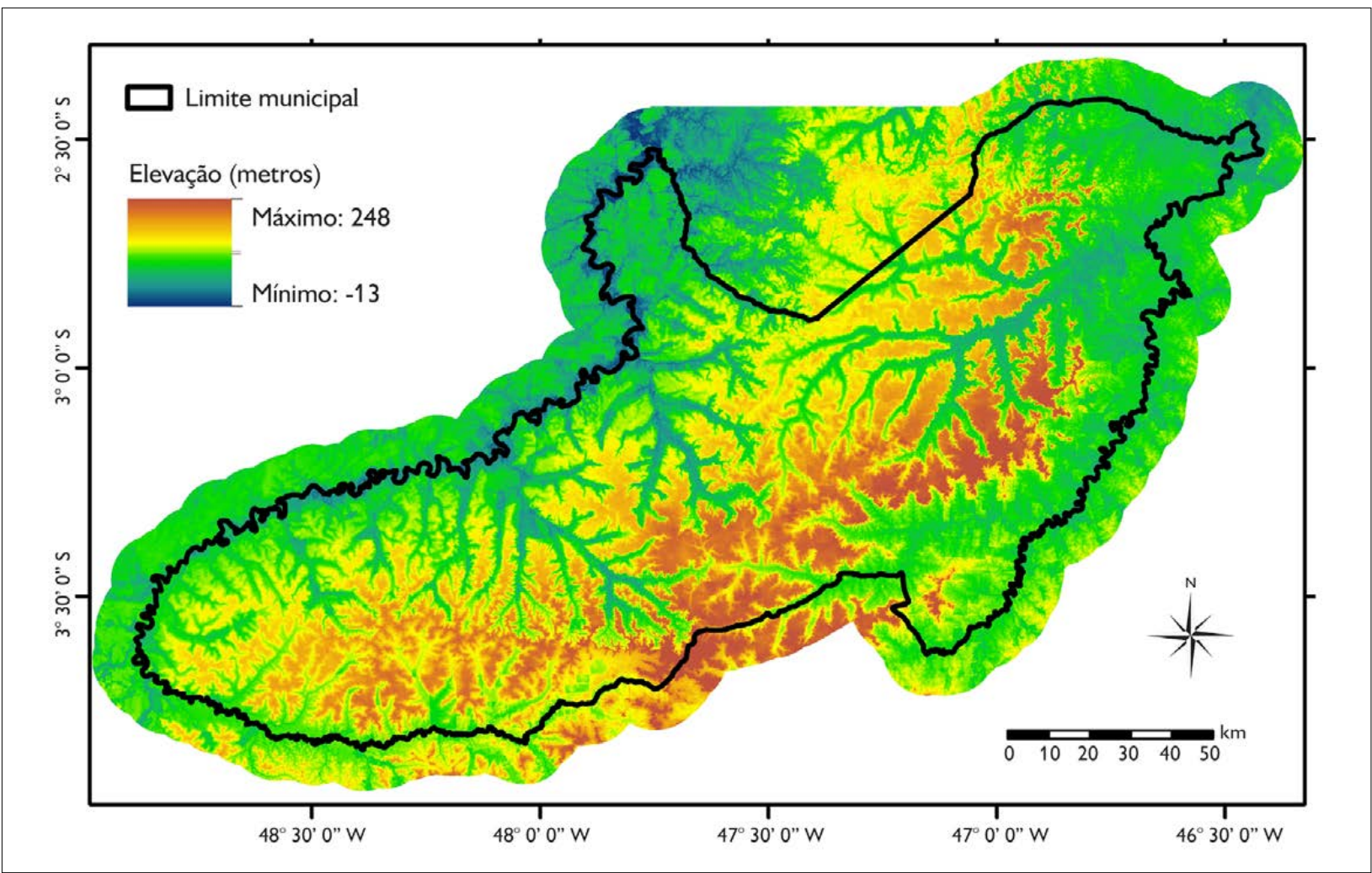

Figura 7. Dados de elevação SRTM para o município de Paragominas.

Após o mapeamento para as classes temáticas, foi feita a junção dos dois conjuntos de dados, 223/62-63 e 222/62-63, gerando o dado de uso/cobertura da terra para o município de Paragominas para o período 1999-2000 (Figura 8). Posteriormente, este dado foi exportado do SPRING, em formato GeoTIFF.

\section{CORREÇÃO DA ALTURA DE DOSSEL}

Para a correção da altura de dossel florestal, foram coletados três pares de amostras de elevação SRTM para cada um dos seguintes pares: floresta madura versus agropecuária, floresta degradada versus agropecuária e floresta secundária versus agropecuária. Em outras palavras, em condição de elevação próxima, foram adquiridas amostras para a classe que iria sofrer a correção de altura (florestas madura, degradada e secundária) e amostras para a classe de referência de altura do chão (agropecuária).
Tabela 1. Imagens Landsat utilizadas na elaboração do dado de uso/ cobertura da terra. Legendas: WRS = Worldwide Reference System; $\mathrm{ETM}+=$ Enhanced Thematic Mapper Plus; TM = Thematic Mapper.

\begin{tabular}{c|c|c|c}
\hline Satélite/Sensor & WRS & Data & Bandas \\
\hline Landsat 7/ETM+ & $222 / 62$ & $07-08-1999$ & $1,2,3,4,5$ e 7 \\
\hline Landsat 7/ETM+ & $222 / 63$ & $07-08-1999$ & $1,2,3,4,5$ e 7 \\
\hline Landsat 5/TM & $223 / 62$ & $05-06-2000$ & $1,2,3,4,5$ e 7 \\
\hline Landsat 5/TM & $223 / 63$ & $05-06-2000$ & $1,2,3,4,5$ e 7 \\
\hline
\end{tabular}

A princípio, cada par seria analisado separadamente. Mas, como os tamanhos das amostras eram muito diferentes e elas não estavam localizadas muito distantes entre si, optou-se por agregar as três amostras das classes das florestas madura, degradada e secundária. Por conseguinte, as da classe agropecuária relacionadas às classes anteriores de floresta também foram agregadas, resultando em três amostras da classe agropecuária. Foi calculado o valor

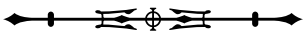




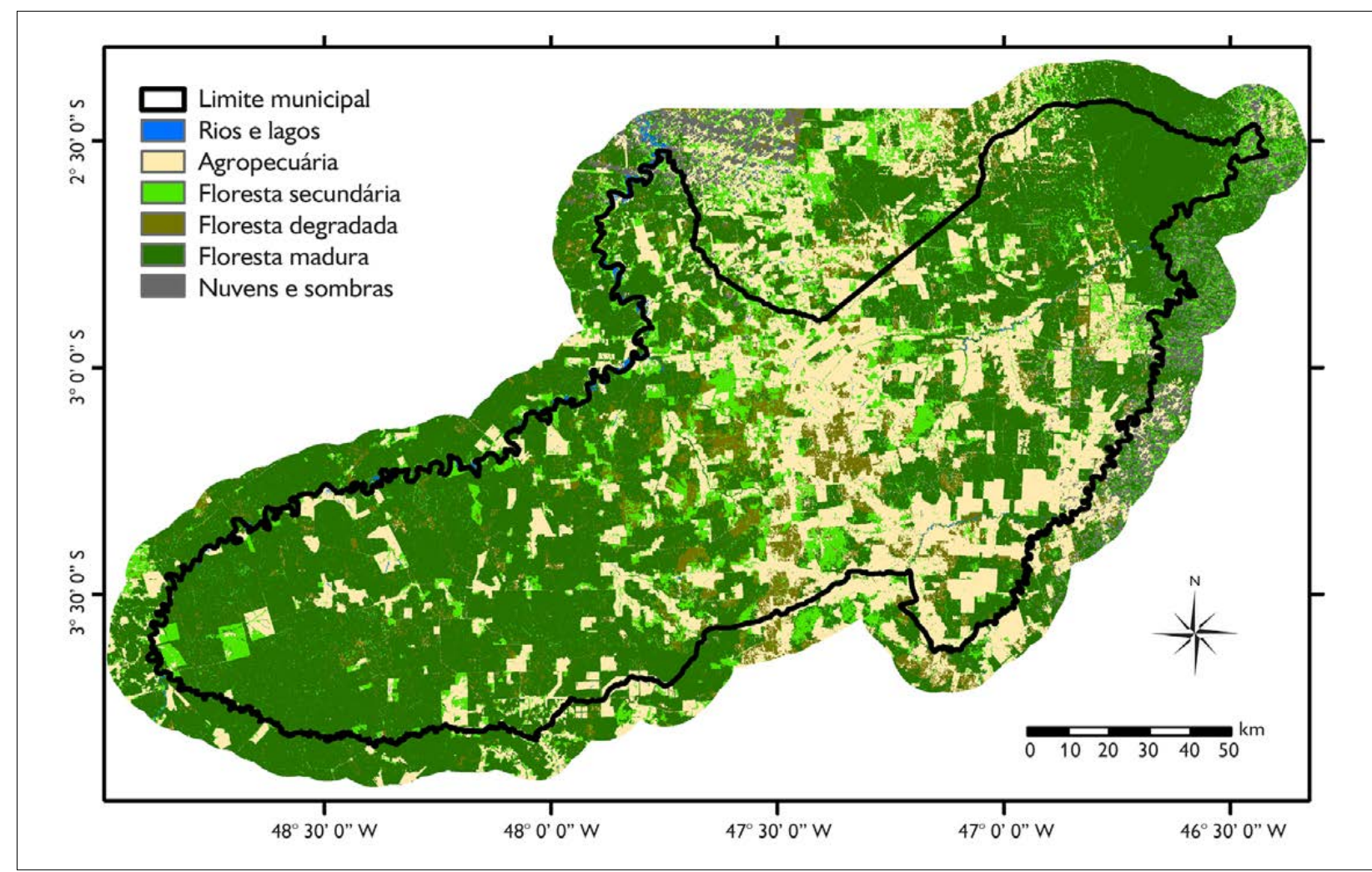

Figura 8. Dado de uso/cobertura da terra para o município de Paragominas (período 1999-2000).

mediano de elevação para cada classe de floresta que iria sofrer a correção de altura e também para cada uma das amostras da classe agropecuária a elas associadas.

O valor de correção de altura de dossel foi definido como a diferença entre os valores da mediana da amostra de elevação das classes a serem corrigidas (florestas madura, degradada e secundária) e da mediana da amostra de elevação da classe agropecuária a ela associada. Esses dados foram definidos como 'correção 1'. Com base nesses valores, foi proposto um segundo valor de correção, mais conservador, a 'correção 2'. Devido à insegurança com relação a esses valores no que se refere às classes de floresta, resolveu-se testar também uma correção intermediária entre as correções 1 e 2, a 'correção 3'.

$\mathrm{Na}$ Tabela 2, são apresentados os valores de correção de altura de dossel em metros, para cada uma das correções propostas. Tomando como referência apenas
Tabela 2. Valores de correção em metros para a altura de dossel em relação às classes com fisionomia florestal e às demais classes de uso/cobertura.

\begin{tabular}{c|c|c|c}
\hline Classes & Correção 1 & Correção 3 & Correção 2 \\
\hline Floresta madura & 20 & 15 & 10 \\
\hline Floresta degradada & 9 & 7 & 5 \\
\hline Floresta secundária & 12 & 7 & 5 \\
\hline Agropecuária & 0 & 0 & 0 \\
\hline Corpos d'água & 0 & 0 & 0 \\
\hline Nuvem e sombra & 0 & 0 & 0 \\
\hline
\end{tabular}

a classe floresta madura, o valor de correção 1 (20 m), definido com base nos valores de elevação das classes de cobertura da terra, representa praticamente o dobro do valor proposto por Rennó (2009), que foi de $11 \mathrm{~m}$. O valor de correção 2 representaria praticamente o mesmo valor (10 m versus 11 m) proposto por Rennó (2009).

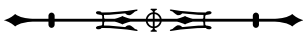


A partir disso, foram geradas três camadas matriciais (raster) de correção, onde as células (pixels) das classes assumiram os respectivos valores de correção de dossel. A elevação corrigida para cada uma das três propostas de correção foi gerada no ArcGIS, fazendo-se a diferença entre a camada sem correção e as camadas para cada uma das correções propostas, ficando-se, dessa forma, com quatro dados de elevação: sem correção de dossel (dado de elevação original), correções de dossel 1, 2 e 3. Para minimizar as variações abruptas resultantes das correções de elevação, um filtro de mediana $(3 \times 3)$ foi aplicado às três correções de dossel e ao dado original, sendo gerados, ao final, oito dados de elevação: 1) sem correção de dossel; 2) sem correção de dossel filtrado; 3) correção de dossel 1; 4) correção de dossel 1 filtrado; 5) correção de dossel 2; 6) correção de dossel 2 filtrado; 7) correção de dossel 3; 8) correção de dossel 3 filtrado.

Para ilustrar o efeito da correção da altura de dossel florestal, foi criado um transecto de 2.000 m (Figuras 9A e 9B), para o qual foram extraídos os valores de elevação para os seguintes dados de elevação: sem correção de dossel (Figura 10A), com correção de dossel 1 (Figura 10B), com correção de dossel 3 (Figura 10C) e com correção de dossel 2 (Figura 10D).

O final do transecto $(2.000 \mathrm{~m})$ fica localizado na porção topográfica mais elevada em uma área de floresta madura (Figuras 9A e 9B). No dado sem correção de dossel, este ponto final do transecto apresenta uma elevação de aproximadamente 120 m (Figura 10A). Após a aplicação da correção de dossel 1 (Tabela 2), essa elevação passa para um valor próximo a 100 m (Figura 10B), o que corresponde à redução de 20 m (correção da altura de dossel). Para as correções de dossel 3 (Figura 10C) e de dossel 2 (Figura 10D), os valores de correção da altura do dossel da floresta madura são menores (Tabela 2). Logo, estes dois últimos apresentam perfis mais suaves, quando comparados ao perfil da correção de dossel 1.

\section{DRENAGEM DAS CARTAS TOPOGRÁFICAS}

\section{$1: 100.000$}

Para avaliar o resultado da extração automática da rede de drenagem, alguns trabalhos fazem apenas uma comparação visual com a drenagem extraída de cartas topográficas (Mark, 1984; Jenson \& Domingue, 1988; Barták, 2009). Outros

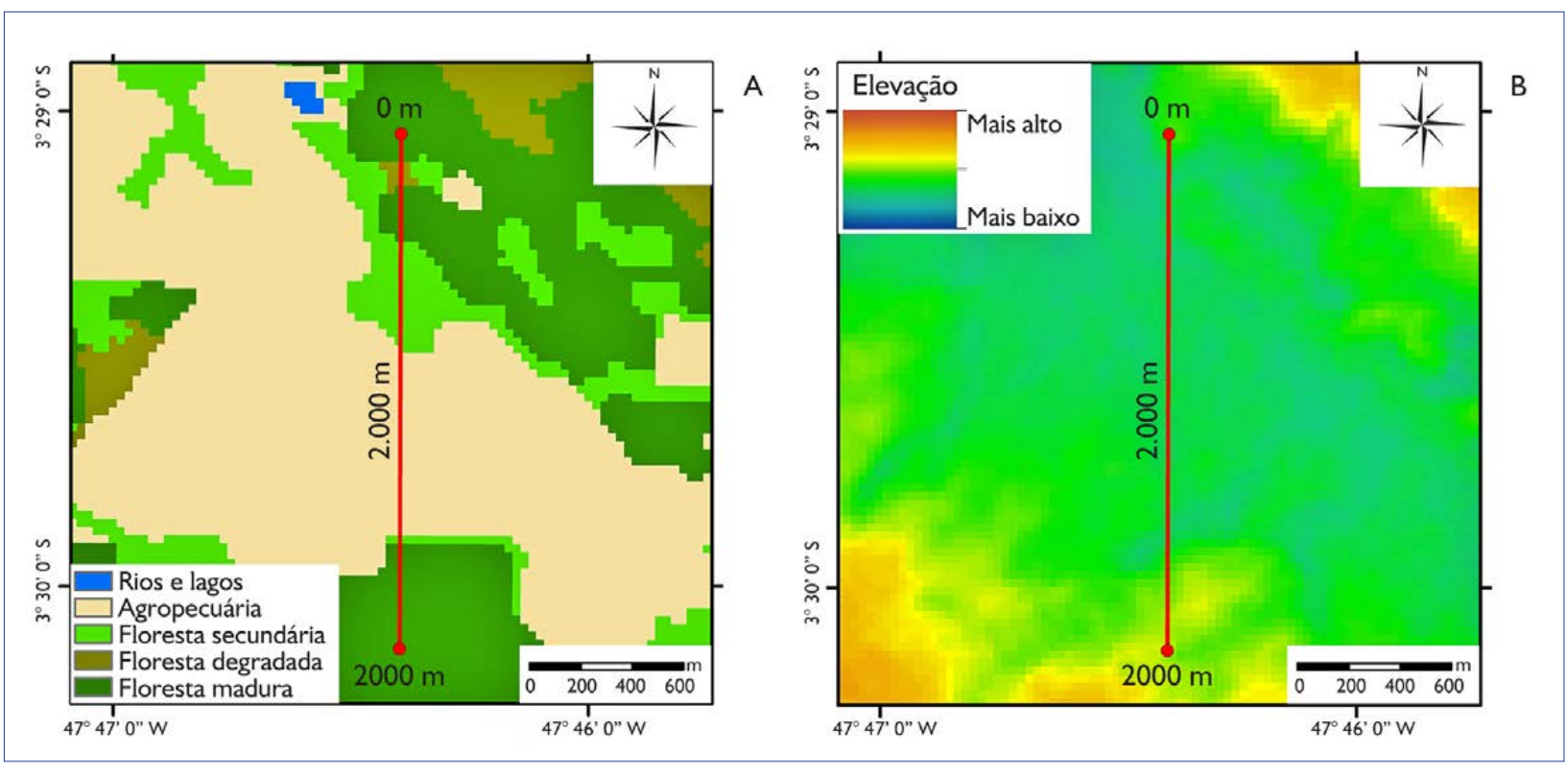

Figura 9. Perfil (horizontal): A) uso/cobertura da terra; B) elevação - sem correção de dossel.

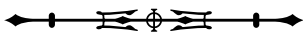




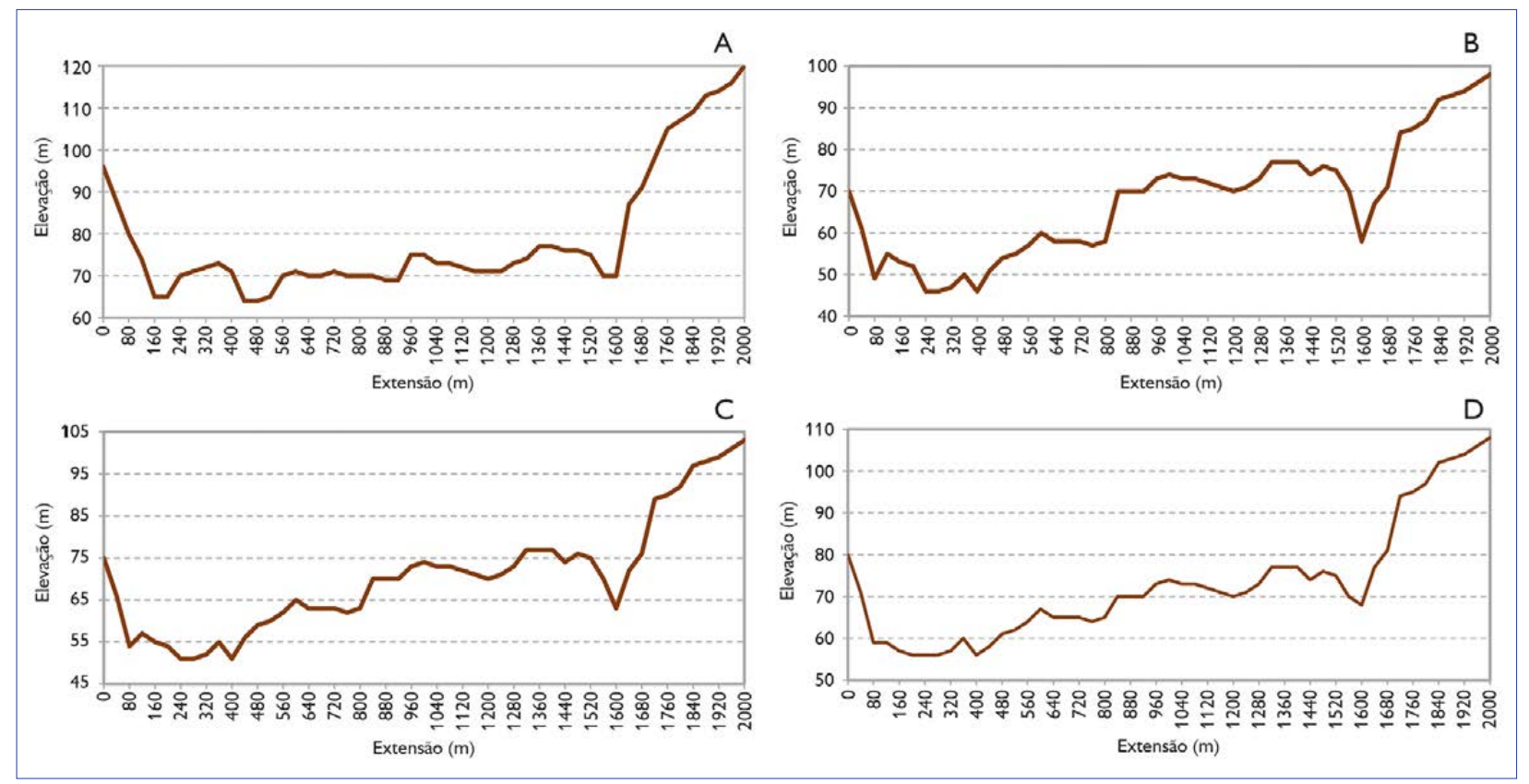

Figura 10. Perfil (vertical) - elevação: A) sem correção de dossel; B) com correção de dossel 1; C) com correção de dossel 3; D) com correção de dossel 2.

trabalhos, para avaliar a precisão da drenagem gerada pelas ferramentas de análises hidrológicas, utilizam como referência uma rede de drenagem, extraída de imagens de satélite, através da digitalização manual (Buarque et al., 2009; Metz et al., 2011; Souza, J. \& Almeida, 2014; Siqueira et al., 2016), e, posteriormente, comparam a extensão das drenagens extraídas automaticamente com as extraídas manualmente. Poggio \& Soille (2011) propõem a utilização de uma superfície de distâncias euclidianas, geradas a partir de uma rede de drenagem de referência extraída de mapas topográficos digitais, para avaliar a precisão da rede de drenagem extraída de forma automática. Ou seja, gera-se uma superfície de distâncias da drenagem extraída e compara-se com a superfície de distâncias de drenagens de referência.

Assim como Poggio \& Soille (2011) fizeram para avaliar a extração da rede de drenagem pelas ferramentas de análise hidrológica Arc Hydro e TerraHidro, foi utilizada uma superfície de distâncias da drenagem gerada a partir das cartas topográficas digitais, escala 1:100.000, disponíveis para o município de Paragominas, pois, como a Figura 11 evidencia, nem todo o município está coberto nesta escala. As cartas topográficas utilizadas foram (DSG, 2017): - Bom Jesus (SA-22-Z-D-II); - Candiru-Açu (SA-23-Y-A-IV); - Fazenda Croantã (SA-23-Y-C-III); - Fazenda Maringá (SA-22-Z-D-III); - Fazenda Rio Capim (SA-22-Z-D-V); - Fazenda Uraim (SA23-Y-A-VI); - Gurupizinho (SA-23-Y-C-V); - Livramento (SA23-Y-A-III); - Paragominas (SA-23-Y-A-V); - Paragominas-S (SA-23-Y-C-II); - Rio Potiritá (SA-23-Y-C-I); - Vila Arco-Íris (SA-23-Y-C-IV); - Vila do Arruaí (SA-23-Y-A-II).

A partir das drenagens das cartas 1:100.000, foi gerada, no ArcGIS, uma superfície de valores de distância euclidiana (dado matricial), com resolução espacial de 50 m (tamanho da célula), onde o valor de cada célula representa a distância, em metros, em relação à drenagem mais próxima. A superfície gerada foi recortada para a área comum entre o dado de drenagem e o limite de Paragominas (Figura 12). Estes valores de distância da drenagem foram utilizados como referência para avaliar as drenagens extraídas pelas ferramentas de análises hidrológicas.

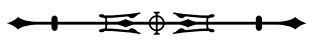




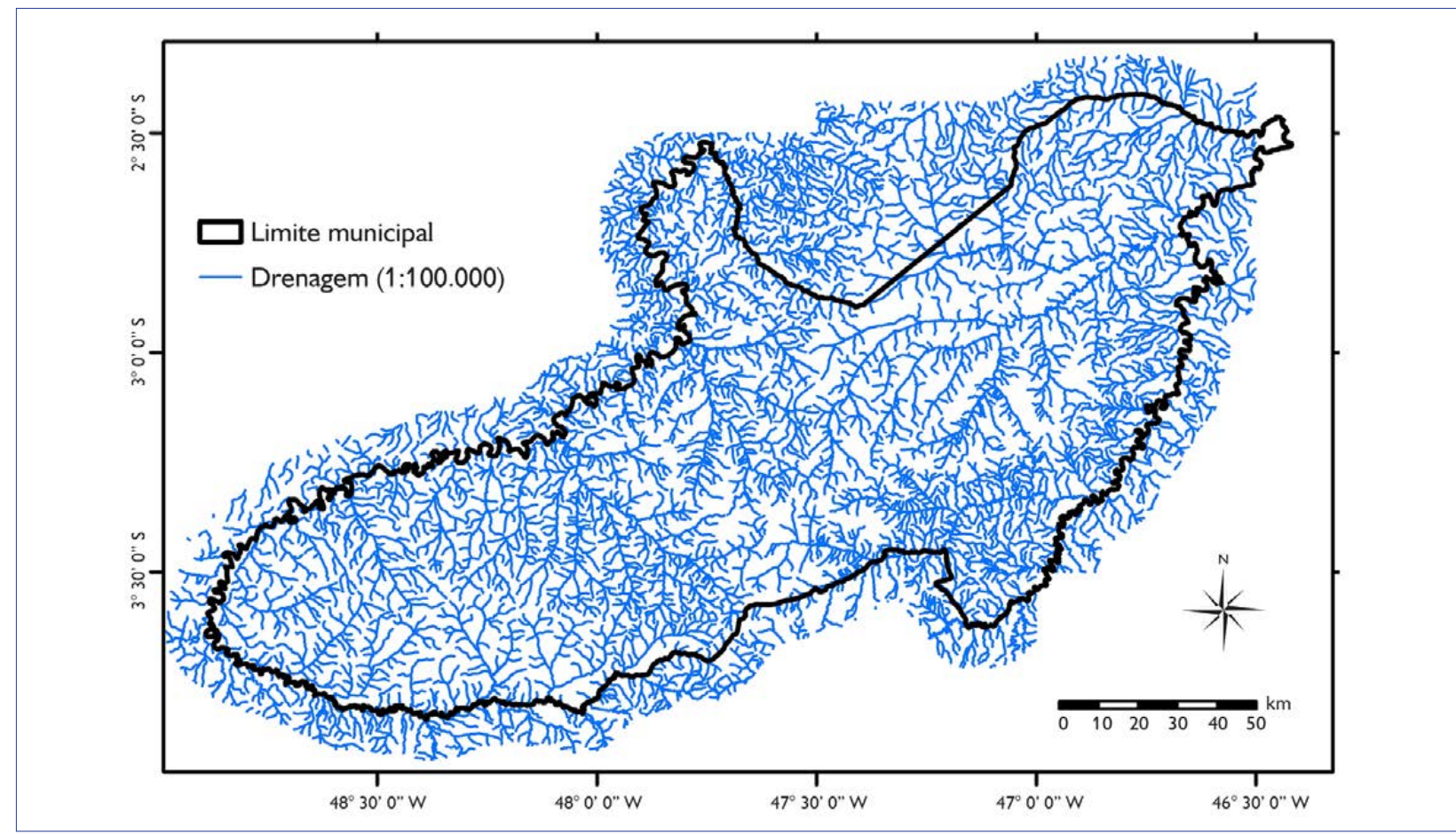

Figura 11. Cobertura das cartas topográficas 1:100.000 para o município de Paragominas.

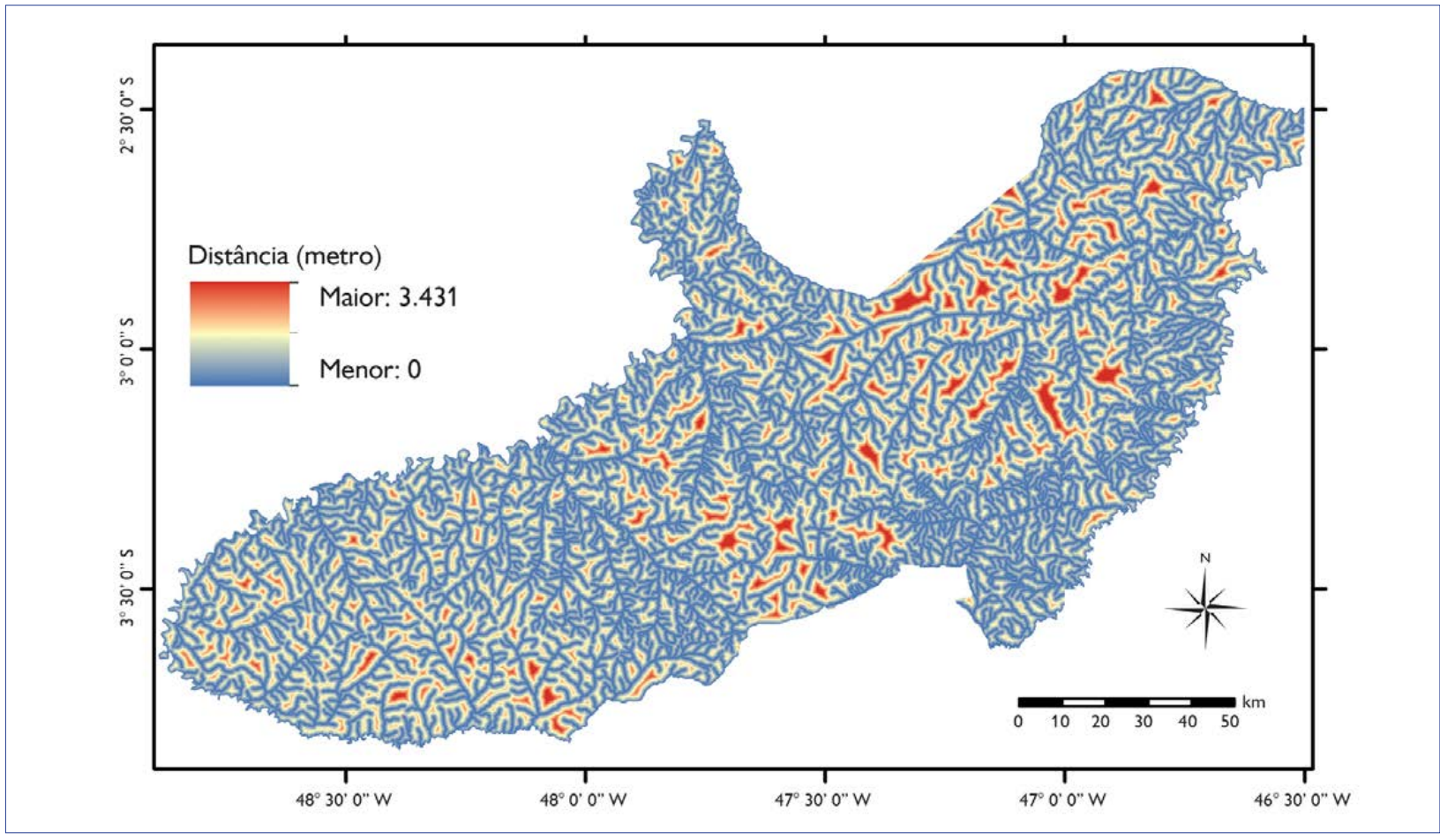

Figura 12. Superfície de distâncias das drenagens: cartas topográficas (1:100.000).

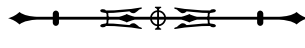




\section{FERRAMENTAS PARA ANÁLISES HIDROLÓGICAS}

Como o objetivo era comparar a drenagem da carta topográfica com a drenagem extraída pelas ferramentas para análises hidrológicas Arc Hydro (ESRI, 2011) e TerraHidro (Rosim et al., 2013; INPE, 2016), foram executados apenas os procedimentos destinados à extração de drenagem (Tabela 3). No caso do Arc Hydro, foram seguidos os passos para a extração de drenagem com padrão dendrítico (ESRI, 2013), pois é o tipo predominantemente encontrado no município de Paragominas (Figura 11). Segundo Riccomini et al. (2000), o padrão de drenagem mais comumente observado é o dendrítico, no qual o arranjo da drenagem assemelha-se à distribuição dos galhos de uma árvore, e ocorre quando a rocha dos substratos é homogênea como um granito ou, ainda, no caso de haver rochas sedimentares com estratos horizontais. Em regiões de topografia muito plana, como as de planícies de alagamento da porção leste da ilha do Marajó, predominam os padrões de drenagem treliça/subtreliça, retangular e paralelo/ subparalelo (Souza, L. \& Rossetti, 2011).

O valor do limiar de acumulação de fluxo foi definido a partir de alguns testes. A drenagem foi extraída a partir de alguns limiares, sendo posteriormente comparada visualmente com a drenagem da carta topográfica, pois se desejava que fosse a mais próxima possível da drenagem desta carta. Foi considerada satisfatória a drenagem extraída utilizando-se o valor de limiar de acúmulo de fluxo de 2.500 células.

Como existiam oito dados de elevação (sem correção de dossel - sem e com filtro de mediana; com correção de dossel 1 - sem e com filtro de mediana; com correção de dossel 3 - sem e com filtro de mediana; e com correção de dossel 2 - sem e com filtro de mediana), e como foram extraídas drenagens utilizando dois pacotes de ferramentas hidrológicas (Arc Hydro e TerraHidro), foram gerados, no total, 16 dados de drenagem.

Entre as drenagens geradas pelos pacotes de ferramentas hidrológicas (Arc Hydro e TerraHidro) a partir dos dados de elevação utilizados (sem correção da altura do dossel versus com correção da altura do dossel, sem filtro de mediana versus com filtro de mediana), verificou-se qual era mais parecida com a drenagem da carta topográfica. Para isso, foram geradas 16 superfícies de distâncias (dado matricial) com resolução espacial de $50 \mathrm{~m}$, a partir das redes de drenagem extraídas, onde o valor de cada célula representa a distância em relação à drenagem mais próxima (Figuras 13A, 13B, 14A e 14B).

Tabela 3. Correspondência entre as etapas para extração de drenagem executadas pelo Arc Hydro (ESRI, 2013) e TerraHidro (Rosim et al., 2013).

\begin{tabular}{c|c}
\hline Arc Hydro - versão 2.0 & TerraHidro - versão 5.0 \\
\hline Dado de elevação SRTM & Dado de elevação SRTM \\
$\begin{array}{c}\text { Correção dos dados de elevação } \\
\text { Preenchimento das depressôes }\end{array}$ & $\begin{array}{c}\text { Correção dos dados de elevação } \\
\text { Eliminação das depressões escavando (PFS), quando não for possível por preenchimento } \\
\text { Eliminação de canais centrais em áreas planas, como espelhos d'água; }\end{array}$ \\
\hline Direção de fluxo & Direção de fluxo \\
\hline Acumulação de fluxo & Área de contribuição \\
\hline Definição de drenagem $=2.500$ células & Rede de drenagem = 2.500 células \\
\hline Segmentação de drenagem & Sem correspondência \\
\hline Processamento da linha de drenagem & Vetorização da rede de drenagem \\
\hline
\end{tabular}

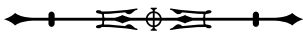



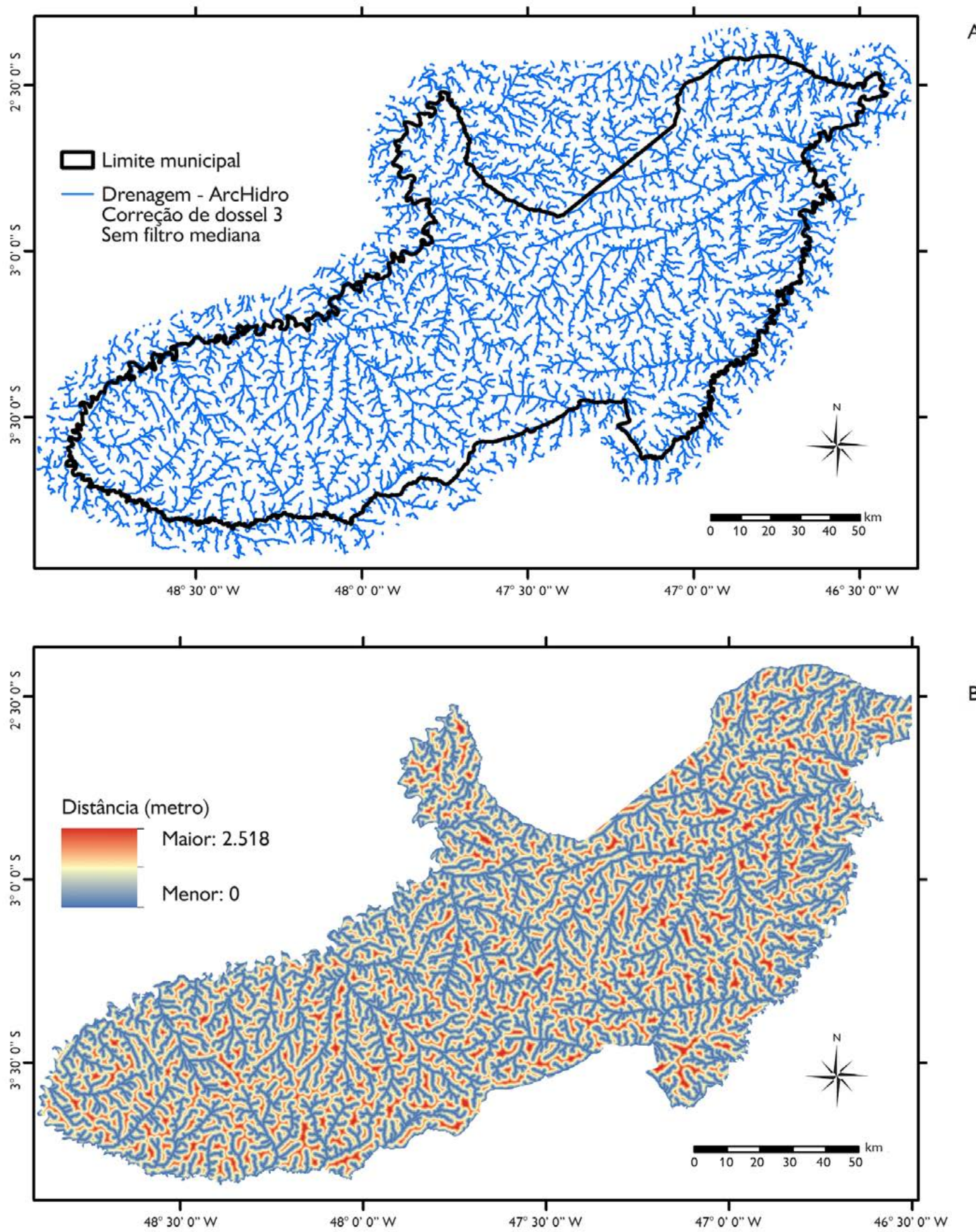

Figura 13. A) Drenagem - Arc Hydro, correção de dossel 3, sem filtro de mediana; B) distâncias da drenagem - Arc Hydro, correção de dossel 3, sem filtro de mediana.

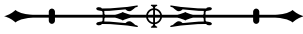




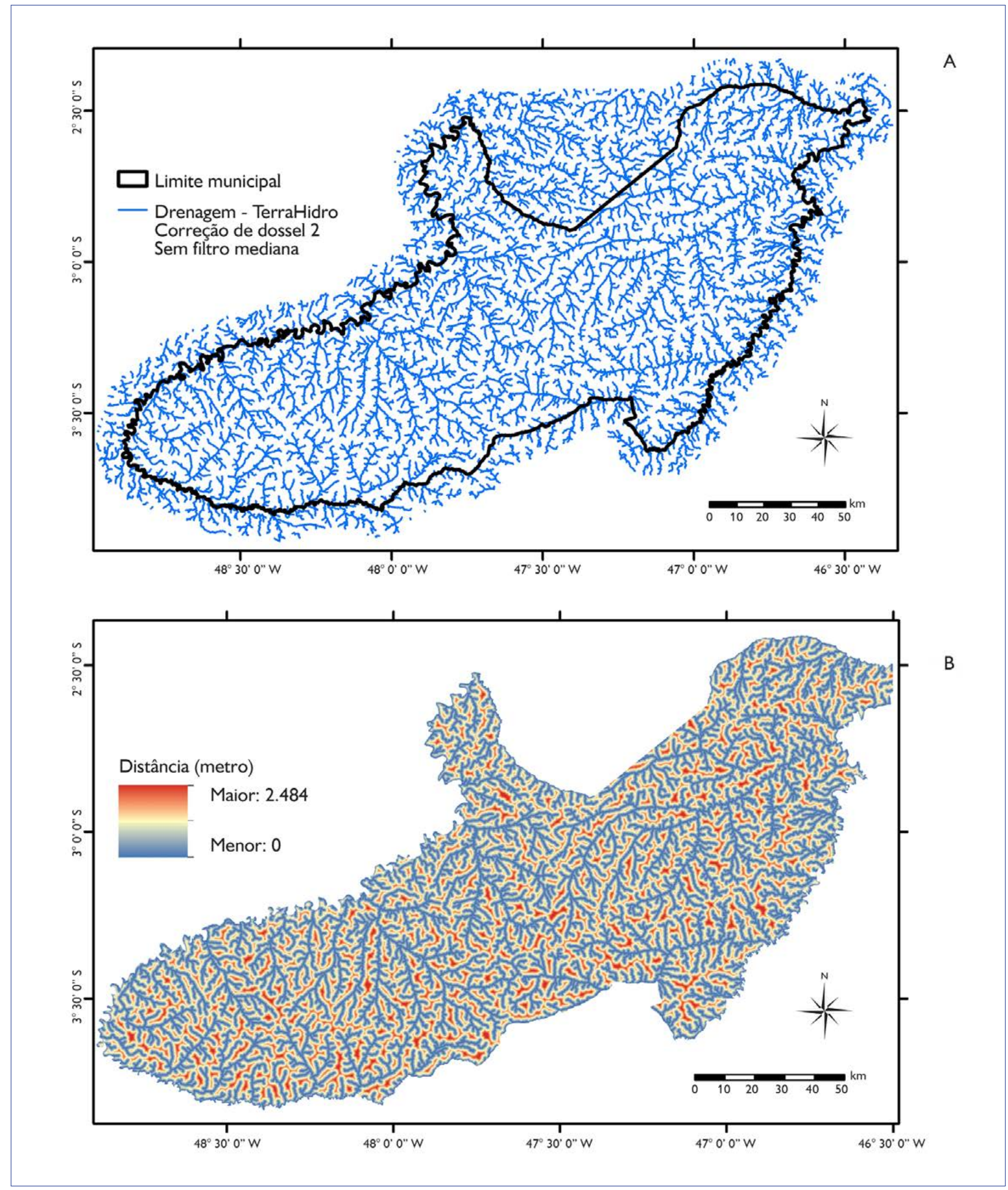

Figura 14. A) Drenagem - TerraHidro, correção de dossel 2, com filtro de mediana; B) distâncias da drenagem - TerraHidro, correção de dossel 2, com filtro de mediana.

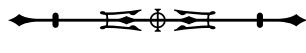




\section{EXTRAÇÃO DOS VALORES DE DISTÂNCIAS DAS DRENAGENS}

Para avaliar as drenagens extraídas pelos programas para estudos hidrológicos (Arc Hydro e TerraHidro), foram realizadas 150 simulações, nas quais eram selecionados 154.444 pontos aleatórios, equivalentes a $2 \%$ dos pixels das superfícies de distâncias, com a condição de uma distância mínima de 300 m entre eles. Nestes pontos, foram extraídos os valores de distância da drenagem das cartas topográficas e também das drenagens extraídas pelo Arc Hydro e pelo TerraHidro para os dados de elevação utilizados (Figuras 15A e 15B). Este procedimento foi realizado no ArcGIS.

Em planilha eletrônica, calculou-se, para cada ponto de cada simulação, o módulo (valor absoluto) da diferença entre o valor da distância da drenagem na superfície de referência (cartas topográficas) e da distância da drenagem nas superfícies derivadas do Arc Hydro e do TerraHidro, ou seja, 154.444 valores. Quanto menor for o valor da diferença do ponto, mais próxima é a drenagem extraída pelos programas hidrológicos (ArcHydro/TerraHidro) da drenagem das cartas topográficas 1:100.000.

Logo, foram gerados 150 valores, que representam uma diferença média entre as distâncias das drenagens das cartas topográficas e as drenagens extraídas pelos pacotes hidrológicos, para cada um dos oito dados de elevação utilizados. A simbologia utilizada para expressar a diferença entre a distância na carta topográfica e a distância obtida pelos pacotes hidrológicos é apresentada na Tabela 4 . Os 150 valores de diferença média para cada um dos 16 pares de comparação (Tabela 4) foram posteriormente importados em pacote estatístico, onde se realizaram análises estatísticas.

\section{ANÁLISES ESTATÍSTICAS}

No pacote estatístico SYSTAT versão 12 (Systat Software, 2009), foram calculadas estatísticas básicas e realizados testes estatísticos, para avaliar médias e variâncias dos pares de comparação - 'sem filtro de mediana' versus 'com filtro de mediana'. As estatísticas básicas calculadas foram: número de amostras, valor mínimo, valor máximo, amplitude, mediana, média aritmética, desvio padrão e variância. Os testes estatísticos tiveram como objetivo a comparação das médias e das variâncias dos valores médios das diferenças de distância da drenagem da carta topográfica e da drenagem extraída pelos pacotes para estudos hidrológicos. Como o número de amostra era grande (150 valores), e os dados representavam valores médios de diferenças de distância, o teorema central do limite pode ser aplicado, sendo aceita a suposição de normalidade (Larson \& Farber, 2015).

O 'teste $F$ ' foi utilizado para a comparação da variância dos valores de diferença de distância da drenagem

Tabela 4. Simbologia utilizada para representar os valores médios da diferença entre as distâncias da drenagem da carta topográfica e das drenagens geradas pelo Arc Hydro e TerraHidro.

\begin{tabular}{c|c}
\hline Carta topográfica versus Arc Hydro & Carta topográfica versus TerraHidro \\
\hline Sem correção de dossel - AHOCD & Sem correção de dossel - TH0CD \\
\hline Sem correção de dossel filtrado - AHOCDF & Sem correção de dossel filtrado - TH0CDF \\
\hline Correção de dossel 1 - AHCD1 & Correção de dossel 1 - THCD1 \\
\hline Correção de dossel 1 filtrado - AHCD1F & Correção de dossel 1 filtrado - THCD1F \\
\hline Correção de dossel 3 - AHCD3 & Correção de dossel 3 - THCD3 \\
\hline Correção de dossel 3 filtrado - AHCD3F & Correção de dossel 3 filtrado - THCD3F \\
\hline Correção de dossel 2 - AHXD2 & Correção de dossel 2 - THXD2 \\
\hline Correção de dossel 2 filtrado - AHXD2F & Correção de dossel 2 filtrado - THXD2F
\end{tabular}

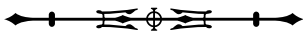



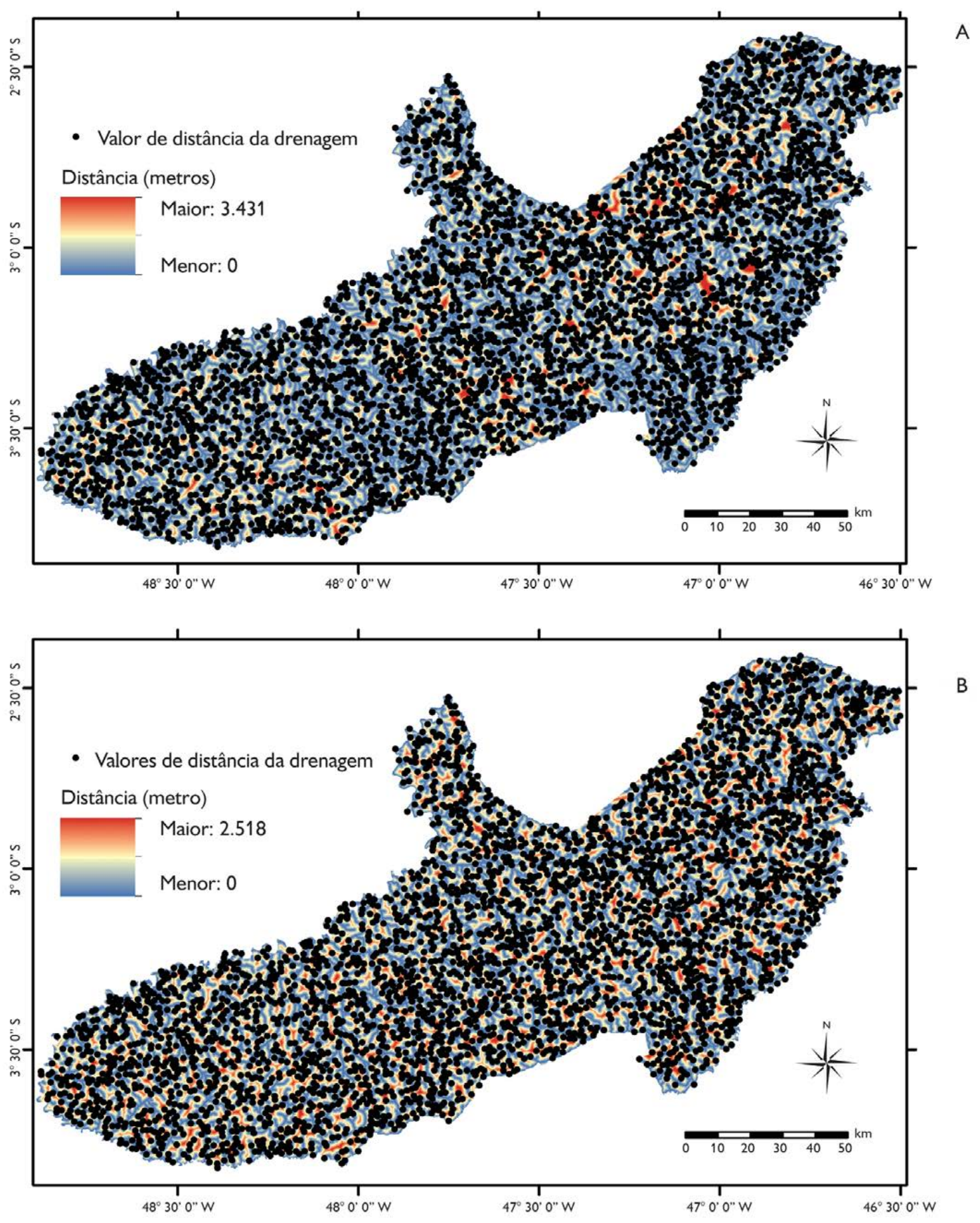

Figura 15. Extração de valores de distâncias das drenagens: A) carta topográfica; B) ArcHidro, correção de dossel 3, sem filtro de mediana.

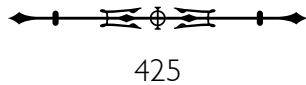


(carta topográfica versus pacotes hidrológicos) - dado sem filtro de mediana versus dado com filtro de mediana (Larson \& Farber, 2015). O teste estatístico utilizado para a comparação das médias dos valores de diferença de distância da drenagem entre o dado sem filtro de mediana e com filtro de mediana foi o 'teste $t$ ' (Larson \& Farber, 2015). Para ambos os testes, o intervalo de confiança utilizado foi de $95 \%(0,95)$, sendo, dessa forma, o nível de significância $(\alpha)$ de $5 \%(\alpha=0,05 ; \alpha / 2=0,025)$. Os testes ' $t$ ' e ' $F$ ' foram realizados no SYSTAT. As hipóteses nula e alternativa referentes às comparações entre os valores médios das diferenças entre 'dado sem filtro de mediana' versus 'dado com filtro de mediana' são apresentadas na Tabela 5.

Em seguida, foi realizada uma análise de variância (ANOVA) para a comparação das médias das distâncias de drenagem extraídas pelos pacotes hidrológicos, utilizando-se apenas os menores valores da comparação 'dado sem filtro de mediana' versus 'dado com filtro de mediana' (Tabela 6). Para a realização da ANOVA, as seguintes condições foram observadas: amostras independentes, distribuição normal e variâncias semelhantes (Larson \& Farber, 2015). A homogeneidade das variâncias foi verificada através do teste de Levene, disponível no SYSTAT. Na ANOVA, o nível de significância utilizado também foi de $5 \%(\alpha=0,05)$. Associado à ANOVA, foi realizado o teste de Tukey, para a comparação de pares de médias. Tanto a ANOVA quanto o teste de Tukey foram realizados por meio do SYSTAT.

\section{RESULTADOS E DISCUSSÕES}

As estatísticas das diferenças de valores de distância entre a drenagem da carta topográfica e as drenagens extraídas
Tabela 5. Testes de hipóteses utilizados.

\begin{tabular}{c|c|c}
\hline $\begin{array}{r}\text { Testes de } \\
\text { hipóteses }\end{array}$ & $\begin{array}{c}\text { Hipótese nula } \\
\left(\mathrm{H}_{0}\right)\end{array}$ & $\begin{array}{c}\text { Hipótese alternativa } \\
\left(\mathrm{H}_{1}\right)\end{array}$ \\
\hline Teste $F$ & $\sigma_{1}=\sigma_{2}$ & $\sigma_{1} \neq \sigma_{2}$ \\
\hline Teste $t$ & $\mu_{1}=\mu_{2}$ & $\mu_{1} \neq \mu_{2}$ \\
\hline
\end{tabular}

utilizando-se o Arc Hydro e o TerraHitro, para os diferentes dados de elevação, são apresentadas nas Tabelas 7 e 8. Como pode ser observado na Tabela 7, no caso de Arc Hydro, as maiores diferenças (média aritmética) são para os dados de elevação sem correção de dossel (AHOCDF e AHOCD), seguidas pelos dados de elevação com correção de dossel 1 (AHCD1F e AHCD1) e pelos dados de elevação com correção de dossel 2 (AHXD2 e AHXD2F). A menor diferença foi verificada para os dados de elevação com correção de dossel 3 (AHCD3 e AHCD3F). A maior diferença observada foi de 298,005 m, para o dado de elevação sem correção de dossel com filtro de mediana (AHOCDF), sendo 283,356 m a menor diferença verificada para o dado de elevação com correção de dossel 3 sem filtro de mediana (AHCD3) (Tabela 7).

$\mathrm{Na}$ Tabela 8, verifica-se que, assim como para o Arc Hydro, para o TerraHidro a maior diferença (média aritmética) também foi registrada para o dado sem correção de dossel (THOCD e THOCDF), e a segunda maior também foi para o dado de elevação com correção de dossel 1 (THCD1 e THCD1F). No caso do TerraHidro, a menor diferença observada foi para o dado com correção de dossel 2 com filtro de mediana (THXD2F), sendo de 270,475 m. Já a maior foi para o dado sem correção de dossel e sem filtro de mediana (THOCD), correspondendo a 278,070 m (Tabela 8).

Tabela 6. Hipóteses da análise de variância (ANOVA).

\begin{tabular}{c|c|c}
\hline Comparações & Hipótese nula $\left(\mathrm{H}_{0}\right)$ & Hipótese alternativa $\left(\mathrm{H}_{1}\right)$ \\
\hline $\begin{array}{c}\text { Arc Hidro - menores distâncias - 'sem filtro } \\
\text { versus com filtro de mediana' }\end{array}$ & $\mu_{1}=\mu_{2}=\mu_{3}=\mu_{4}$ & Ao menos uma das médias é diferente $\left(\mu_{1}, \mu_{2}, \mu_{3}, \mu_{4}\right)$ \\
\hline $\begin{array}{c}\text { TerraHidro - menores distâncias - 'sem filtro } \\
\text { versus com filtro de mediana' }\end{array}$ & $\mu_{1}=\mu_{2}=\mu_{3}=\mu_{4}$ & Ao menos uma das médias é diferente $\left(\mu_{1}, \mu_{2}, \mu_{3}, \mu_{4}\right)$ \\
\hline
\end{tabular}


Tabela 7. Estatísticas para os valores de diferenças médias de distâncias entre a drenagem da carta topográfica e as drenagens extraídas pelo Arc Hydro, para os diversos dados de elevação. Legenda: * = sem filtro x com filtro: maiores diferenças em vermelho (pior) e menores em azul (melhor). Números em negrito referem-se aos valores melhor (azul) e pior (vermelho).

\begin{tabular}{c|c|c|c|c|c|c|c|c}
\hline Estatísticas & AHOCD & AHOCDF & AHCD1 & AHCD1F & AHCD3 & AHCD3F & AHXD2 & AHXD2F \\
\hline Número de amostras & 150 & 150 & 150 & 150 & 150 & 150 & 150 & 150 \\
\hline Mínimo & 293,858 & 295,851 & 283,788 & 285,051 & 281,807 & 282,146 & 283,291 & 283,113 \\
\hline Máximo & 297,266 & 299,812 & 287,492 & 288,509 & 285,576 & 285,634 & 286,942 & 286,679 \\
\hline Amplitude & 3,408 & 3,961 & 3,705 & 3,457 & 3,769 & 3,488 & 3,651 & 3,566 \\
\hline Mediana & 295,512 & 298,027 & 285,212 & 286,667 & 283,276 & 283,809 & 285,034 & 284,966 \\
\hline Média aritmética* & 295,512 & 298,005 & 285,254 & 286,687 & 283,356 & 283,882 & 285,070 & 284,982 \\
\hline Desvio padrão & 0,648 & 0,670 & 0,680 & 0,656 & 0,685 & 0,682 & 0,674 & 0,672 \\
\hline Variância & 0,420 & 0,449 & 0,462 & 0,431 & 0,469 & 0,465 & 0,454 & 0,451 \\
\hline
\end{tabular}

Tabela 8. Estatísticas dos 150 valores de diferenças de distâncias da drenagem entre a carta topográfica e o TerraHidro, para os diferentes dados de elevação. Legenda: * = sem filtro x com filtro: maiores diferenças em vermelho (pior) e menores em azul (melhor). Números em negrito referem-se aos valores melhor (azul) e pior (vermelho).

\begin{tabular}{c|c|c|c|c|c|c|c|c}
\hline Estatísticas & THOCD & THOCDF & THCD1 & THCD1F & THCD3 & THCD3F & THXD2 & THXD2F \\
\hline Número de amostras & 150 & 150 & 150 & 150 & 150 & 150 & 150 & 150 \\
\hline Mínimo & 276,623 & 275,517 & 272,451 & 271,031 & 270,983 & 269,344 & 270,255 & 268,855 \\
\hline Máximo & 280,082 & 278,918 & 276,137 & 274,79 & 274,39 & 272,858 & 273,961 & 272,326 \\
\hline Amplitude & 3,459 & 3,401 & 3,686 & 3,759 & 3,407 & 3,513 & 3,707 & 3,471 \\
\hline Mediana & 278,010 & 276,984 & 273,884 & 272,827 & 272,26 & 270,928 & 271,775 & 270,367 \\
\hline Média aritmética* & 278,070 & 276,993 & 273,956 & 272,902 & 272,354 & 271,025 & 271,850 & 270,475 \\
\hline Desvio padrão & 0,632 & 0,613 & 0,670 & 0,643 & 0,664 & 0,662 & 0,639 & 0,616 \\
\hline Variância & 0,399 & 0,376 & 0,449 & 0,414 & 0,441 & 0,438 & 0,408 & 0,379 \\
\hline
\end{tabular}

Em relação ao Arc Hydro, quando se observam as diferenças médias de distâncias entre as drenagens extraídas do dado de elevação sem filtro de mediana e com filtro de mediana, pode-se ver que, para o dado de elevação com correção de dossel 2, a distância média do dado sem filtro de mediana, ainda que muito pequena, foi maior do que a do dado com filtro de mediana. Para todos os demais dados de elevação (sem correção de dossel, com correção de dossel 1 e com correção de dossel 3), a diferença média de distância foi menor para o dado sem filtro de mediana (Tabela 7).

Já para o TerraHidro, quando comparados os dados de elevação sem filtro de mediana com o com filtro de mediana, observou-se comportamento oposto com relação ao Arc Hydro. Ou seja, para todos os dados de elevação (sem correção de dossel, com correções de dossel 1, 2 e 3), o dado com filtro de mediana apresentou uma diferença média de distância menor do que o dado sem filtro de mediana (Tabela 8).

Nas Figuras 16A e 16B, podem ser visualizadas as diferenças de distâncias médias entre as drenagens extraídas pelo Arc Hydro (Figura 16A) e pelo TerraHidro (Figura 16B), a partir dos dados de elevação sem correção de dossel, com as três correções de elevação examinadas e a drenagem de referência (carta topográfica 1:100.000), mas apenas para o menor valor da comparação entre 'dado sem filtro de mediana' versus 'dado com filtro de mediana'.

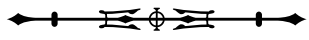


Como não foram muito grandes as diferenças entre as médias das distâncias entre o mesmo dado de elevação sem o filtro de mediana e com o filtro de mediana, foram realizados testes estatísticos para a comparação da variância (teste $F$ ) e da média (teste $t$ ) dos valores médios das 150 simulações de diferença de distância entre a drenagem presentes nas cartas topográficas e as extraídas pelos pacotes hidrológicos (Arc Hydro e TerraHidro). Uma síntese dos testes de hipótese é apresentada nas Tabelas 9 e 10.
Com base nos testes de hipóteses, verificou-se que as variâncias dos dados sem filtro de mediana não apresentaram diferenças significativas, quando comparadas às variâncias dos dados com filtro de mediana (test $F$ ), tanto no caso do Arc Hydro (Tabela 9) quanto no do TerraHidro (Tabela 10). Com relação às médias (test $t$ ), o único caso em que a comparação 'dado sem filtro' versus 'dado com filtro' não apresentou diferença estatística significativa foi para a drenagem extraída pelo Archydro para o dado
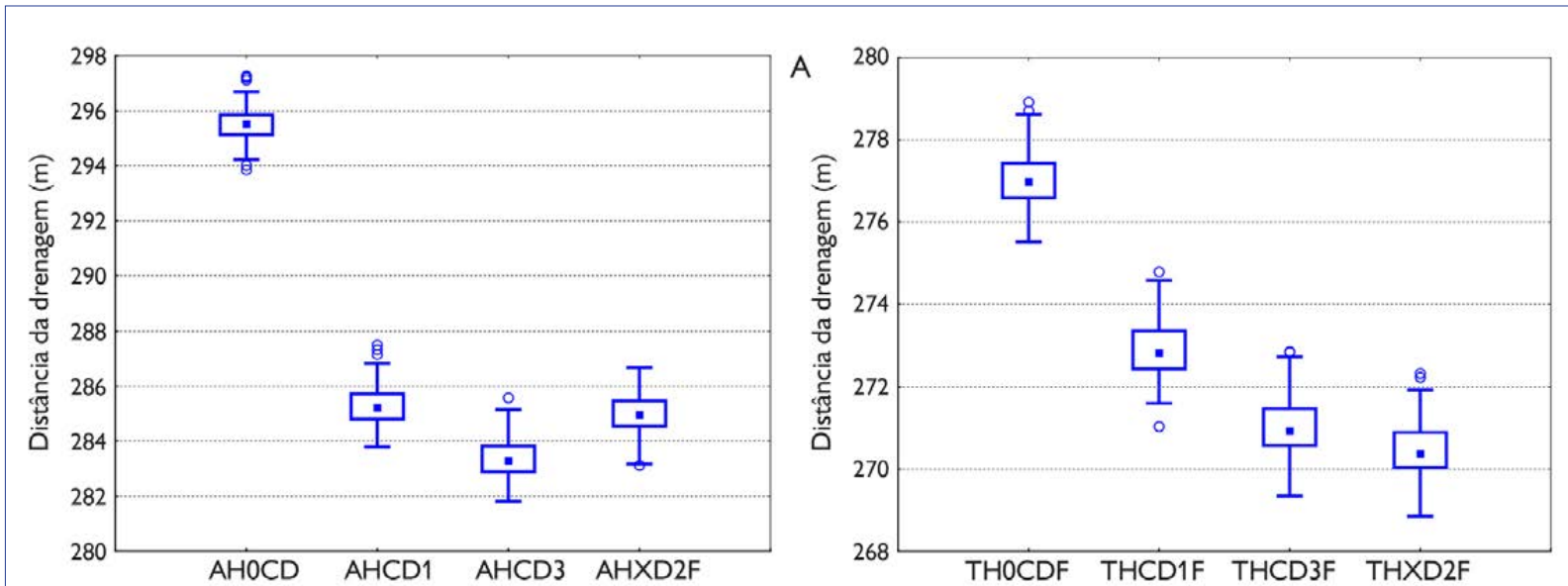

Figura 16. Valores médios de distância da drenagem: A) Arc Hydro; B) TerraHidro.

Tabela 9. Síntese dos testes de hipóteses - Arc Hydro.

\begin{tabular}{c|c|c|c|c} 
Comparação & $\begin{array}{c}\text { Teste } F \\
\text { Valor-P }\end{array}$ & $\begin{array}{c}\text { Teste } F \\
\text { Conclusão }\end{array}$ & $\begin{array}{c}\text { Test } t \\
\text { Valor-P }\end{array}$ & $\begin{array}{c}\text { Test } t \\
\text { Conclusão }\end{array}$ \\
\hline AHOCD versus AHOCDF & 0,688 & Variâncias iguais & $<0,001$ & Médias diferentes \\
\hline AHCD1 versus AHCD1F & 0,671 & Variâncias iguais & $<0,001$ & Médias diferentes \\
\hline AHCD3 versus AHCD3F & 0,960 & Variâncias iguais & $<0,001$ & Médias diferentes \\
\hline AHXD2 versus AHXD2F & 0,966 & Variâncias iguais & 0,258 & Médias iguais \\
\hline
\end{tabular}

Tabela 10. Síntese dos testes de hipóteses - TerraHidro.

\begin{tabular}{c|c|c|c|c}
\hline Comparação & $\begin{array}{c}\text { Teste } F \\
\text { Valor-P }\end{array}$ & $\begin{array}{c}\text { Test } F \\
\text { Conclusão }\end{array}$ & $\begin{array}{c}\text { Test } t \\
\text { Valor-P }\end{array}$ & $\begin{array}{c}\text { Test } t \\
\text { Conclusão }\end{array}$ \\
\hline TH0CD versus TH0CDF & 0,722 & Variâncias iguais & $<0,001$ & Médias diferentes \\
\hline THCD1 versus THCD1F & 0,613 & Variâncias iguais & $<0,001$ & Médias diferentes \\
\hline THCD3 versus THCD3F & 0,964 & Variâncias iguais & $<0,001$ & Médias diferentes \\
\hline THXD2 versus THXD2F & 0,658 & Variâncias iguais & $<0,001$ & Médias diferentes \\
\hline
\end{tabular}

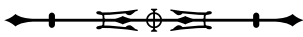


com correção de dossel 2 (Tabelas 7 e 9). Para todos os demais casos de comparação das médias ('dado sem filtro' versus 'dado com filtro'), seja para o Arc Hydro ou para o TerraHidro, as diferenças foram significativas (Tabelas 7 a 10).

Uma vez que as condições para a realização da ANOVA foram satisfeitas, foram feitas as comparações das médias das diferenças de distância das drenagens extraídas com relação às drenagens de referência, para os menores valores da comparação 'sem filtro de mediana' versus 'com filtro de mediana' (Figuras 16A e 16B), ainda que não houvesse diferença significativa para a drenagem extraída pelo Arc Hydro com correção de dossel 2 (AHXD2 e AHXD2F): - Arc Hidro: AHOCD versus AHCD1 versus AHCD3 versus AHXD2F.

- TerraHidro: THOCDF versus THCD1F versus THCD3F versus THXD2F.

Os resultados da ANOVA, com o teste de Tukey, para as drenagens extraídas pelo Arc Hidro são apresentados nas Tabelas 11 e 12. Para o TerraHidro, os resultados são apresentados nas Tabelas 13 e 14. Os resultados da ANOVA indicam que ao menos uma das médias foi diferente para as drenagens extraídas pelo Arc Hidro (Tabela 11), assim como para as drenagens extraídas pelo TerraHidro (Tabela 13). Os testes de Tukey possibilitam afirmar que todas as médias foram diferentes, tanto das drenagens extraídas pelo Arc Hidro (Tabela 12), quanto das drenagens extraídas pelo TerraHidro (Tabela 14).

Com base na ANOVA, tem-se a segurança de afirmar que o menor valor médio de distância da drenagem de referência obtido pelo Arc Hydro foi de 283,356 m, utilizando-se o dado de elevação com a correção de dossel 3 e sem o filtro de mediana - AHCD3 (Tabelas 7, 11 e 12; Figura 16A), e que ela foi significativamente diferente das demais. Assim como é possível afirmar que o menor valor médio de distância da drenagem obtido pelo TerraHidro foi de 270,475 m, utilizando-se o dado de elevação com a correção de dossel 2 e com o filtro de mediana THXD2F (Tabelas 8, 13 e 14; Figura 16B), também sendo significativamente diferente das demais.
Ao final, procedeu-se a comparação entre o melhor resultado de extração da rede de drenagem conseguido pelo Arc Hydro - diferença média de 283,356 m (AHCD3) - e o melhor resultado de extração de rede de drenagem conseguido pelo TerraHidro - diferença média de 270,475 m (THXD2F). A síntese dos resultados pode ser visualizada na Tabela 15 e na Figura 17.

Tabela 11. ANOVA - Arc Hidro. Legendas: GL = graus de liberdade; $\mathrm{SQ}=$ soma dos quadrados; $\mathrm{QM}=$ quadrado médio.

\begin{tabular}{c|c|c|c|c|c}
\hline Fonte & GL & SQ & QM & Valor $F$ & Valor-P \\
\hline Agrupador & 3 & 13881,8 & 4627,26 & 10269,65 & $<0,001$ \\
\hline Erro & 596 & 268,5 & 0,45 & & \\
\hline Total & 599 & 14150,3 & & & \\
\hline
\end{tabular}

Tabela 12. Testes de Tukey (Valor-P) - Arc Hidro.

\begin{tabular}{c|c|c|c}
\hline & AHCD1 & AHCD3 & AHXD2F \\
\hline AH0CD & $<0,001$ & $<0,001$ & $<0,001$ \\
\hline AHCD1 & & $<0,001$ & 0,0026 \\
\hline AHCD3 & & & $<0,001$ \\
\hline
\end{tabular}

Tabela 13. ANOVA - TerraHidro. Legendas: $G L=$ graus de liberdade; $\mathrm{SQ}=$ soma dos quadrados; $\mathrm{QM}=$ quadrado médio.

\begin{tabular}{c|c|c|c|c|c}
\hline Fonte & GL & SQ & QM & Valor $F$ & Valor-P \\
\hline Agrupador & 3 & 3920,3 & 1306,75 & 3252,13 & $<0,001$ \\
\hline Erro & 596 & 239,5 & 0,40 & & \\
\hline Total & 599 & 4159,7 & & & \\
\hline
\end{tabular}

Tabela 14. Testes de Tukey (Valor-P) - TerraHidro.

\begin{tabular}{c|c|c|c}
\hline & AHCD1 & AHCD3 & AHXD2F \\
\hline AH0CD & $<0,001$ & $<0,001$ & $<0,001$ \\
\hline AHCD1 & & $<0,001$ & $<0,001$ \\
\hline AHCD3 & & & $<0,001$ \\
\hline
\end{tabular}

Tabela 15. Síntese dos testes de hipóteses - ArcHydro versus TerraHidro.

\begin{tabular}{c|c|c|c|c}
\hline Comparação & $\begin{array}{c}\text { Teste } F \\
\text { Valor-P }\end{array}$ & $\begin{array}{c}\text { Teste } F \\
\text { Conclusão }\end{array}$ & $\begin{array}{c}\text { Teste } t \\
\text { Valor-P }\end{array}$ & $\begin{array}{c}\text { Test } t \\
\text { Conclusão }\end{array}$ \\
\hline $\begin{array}{c}\text { AHCD3 versus } \\
\text { THXD2F }\end{array}$ & 0,198 & $\begin{array}{c}\text { Variâncias } \\
\text { iguais }\end{array}$ & $<0,001$ & $\begin{array}{c}\text { Médias } \\
\text { diferentes }\end{array}$ \\
\hline
\end{tabular}

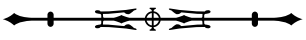


A diferença entre a menor distância da drenagem conseguida pelo Arc Hydro e pelo TerraHidro foi de $12,881 \mathrm{~m}$, sendo significativa (Tabela 11 e Figura 17). As variâncias, por sua vez, não apresentaram diferenças significativas (Tabela 11 e Figura 17). Ou seja, de forma resumida, a melhor drenagem extraída pelo TerraHidro ficou 12,881 m, em média, mais próxima da drenagem de referência, quando comparada com a melhor drenagem extraída pelo Arc Hydro. Estes resultados mostram que a drenagem extraída pelo TerraHidro, utilizando dados de elevação com correção de dossel 2 - com filtro de mediana - apresenta menor diferença com relação à drenagem das cartas topográficas (1:100.000), quando comparada com a drenagem extraída pelo Arc Hydro, utilizando o dado de elevação com correção de dossel 3 - sem filtro de mediana -, demonstrando desempenho melhor do TerraHidro, ao ser comparado com o Arc Hydro, no que concerne à extração da drenagem a partir de dados de elevação SRTM para o município de Paragominas.

Esse melhor desempenho da extração de drenagem pelo TerraHidro com relação ao Arc Hydro está associado ao fato de o primeiro eliminar as depressões do dado de elevação por escavação (algoritmo PFS), quando não for possível eliminá-las por preenchimento (Rosim et al., 2013), alterando menos a estrutura do MDE (Jones, 2002), ao passo que o Arc Hydro elimina as depressões apenas por preenchimento (ESRI, 2011).

Rosim et al. (2013) já haviam observado, ao comparar as drenagens extraídas pelo TerraHidro e pelo Arc Hydro para a bacia do rio Purus, que o primeiro produz uma drenagem mais realista do que o segundo. Este rio é muito largo, apresentando $350 \mathrm{~m}$ na cidade de Lábrea (Google, 2018), estado do Amazonas, além possuir extensas planícies de inundação. O resultado já era esperado, pois o algoritmo para a extração de drenagem do TerraHidro tem bom desempenho neste tipo de paisagem (Siqueira et al., 2016). No caso do município de Paragominas, a paisagem é bem diferente da bacia do Purus, predominando os vales bem encaixados (Figura 7).

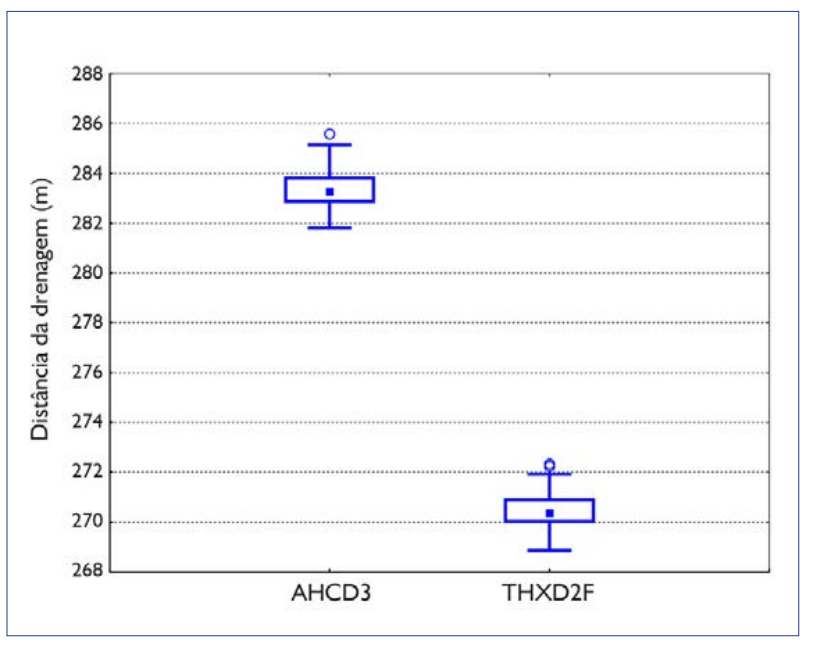

Figura 17. Menores valores de distância da drenagem extraída pelo Arc Hydro (AHCD3) e pelo TerraHidro (THXD2F).

Ainda assim, a drenagem extraída pelo TerraHidro teve maior similaridade com a das cartas topográficas do que a extraída com o Arc Hydro.

Buarque et al. (2009), analisando a extração de drenagens por diferentes ferramentas implementadas em SIG distintos (ArcGIS/Arc Hydro - preenchimento de depressões; IDRISI - Priority-First Search - PFS), verificaram que, quando utilizada uma zona-tampão (buffer) como área válida para extração de drenagem, a tendência para rios largos, como o Purus, foi de que todos os algoritmos gerassem resultados semelhantes. Porém, em rios mais estreitos, como o Ituxi, ainda que utilizando uma zonatampão como área válida para extração de drenagem, a gerada pelo IDRISI (algoritmo PSF) foi a que mais se aproximou da tida como verdadeira.

Siqueira et al. (2016), comparando a extração da rede de drenagem pelo IPH-Hydro Tools com a rede de drenagem extraída pelo ArcGIS/Arc Hydro e IDRISI, observaram que a drenagem extraída pelos programas que utilizam PFS (IPH-Hydro Tools e IDRISI) apresentaram um erro bem menor do que os programas que utilizam preenchimento de depressões (Arc Hydro). Para o rio Taquari, bacia Taquari-Antas, estado do Rio Grande do Sul, o erro de posicionamento da drenagem extraída

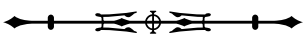


pelo Arc Hydro foi estimado como sendo 2,7 vezes maior do que o posicionamento da drenagem extraída pelo IPH-Hydro Tools e pelo IDRISI. Para o rio Iquiri, bacia do Purus, no estado do Acre, região mais plana, o erro foi ainda maior (3,5 vezes). Os resultados obtidos por Buarque et al. (2009) e por Siqueira et al. (2016) corroboram os obtidos neste estudo.

\section{CONCLUSÕES}

A correção dos dados de elevação SRTM, descontando a altura do dossel florestal, foi um procedimento importante para melhor extração da rede de drenagem, tanto para o Arc Hydro quanto para o TerraHidro. No entanto, as ferramentas hidrológicas responderam de formas diferentes aos valores de correção. $\bigcirc$ Arc Hydro registrou melhor resultado quando o dossel da floresta madura teve um rebaixamento intermediário (correção $3=15 \mathrm{~m}$ ), enquanto que o TerraHidro teve melhor extração de drenagem com um rebaixamento menor (correção $2=$ 10 m). Dessa forma, recomenda-se a remoção da elevação referente à altura do dossel florestal antes de se proceder a extração da drenagem, tanto com o Arc Hydro quanto com o TerraHidro.

A aplicação do filtro de mediana melhorou a extração da drenagem pelo TerraHidro para os dados SRTM, com e sem correção da altura do dossel. A partir deste resultado, recomenda-se a aplicação do filtro de mediana nos dados SRTM antes de se proceder a extração da drenagem utilizando o TerraHidro. Para a extração da drenagem com o Arc Hydro, o resultado da aplicação do filtro de mediana aos dados SRTM resultou em melhoria em apenas um caso; mesmo assim, a melhora foi muito pequena, não sendo significativa estatisticamente. Assim, não se recomenda a aplicação do filtro de mediana aos dados SRTM quando se proceder a extração da drenagem com o Arc Hydro.

Por fim, a ferramenta para análises hidrológicas TerraHidro resultou na extração de uma rede de drenagem com uma menor diferença em relação às drenagens das cartas topográficas 1:100.000, quando comparada à extração da ferramenta Arc Hydro. Dessa forma, na sequência de estudos sobre a paisagem do município de Paragominas, a ferramenta TerraHidro será utilizada na extração de uma rede de drenagem detalhada, ou seja, na definição da rede de drenagem e de delimitação das microbacias hidrográficas, será utilizado um limiar de área bem inferior a 2.500 células, como foi adotado neste estudo.

\section{AGRADECIMENTOS}

Os autores agradecem aos revisores que, com sua colaboração voluntária, contribuíram para a melhoria do artigo.

\section{REFERÊNCIAS}

ABRAMS, M., B. BAILEY, H. TSU \& M. HATO, 2010. The ASTER Global DEM. Photogrammetric Engineering and Remote Sensing 76(4): 344-348.

AMES, D. P., P. MEEMS, J. FAUST, O. LEPRÊTRE, S. LESCHINSKY \& R. ANGELETTI, 2018. About the MapWindow GIS open source project. Disponível em: <http://www.mapwindow.org/> . Acesso em: 4 março 2018.

BARTÁK, V., 2009. How to extract river networks and catchment boundaries from DEM: a review of digital terrain analysis techniques. Journal of Landscape Studies 2(1): 57-68.

BRAZ, L. C., J. L. G. PEREIRA, L. V. FERREIRA \& M. C. THALÊS, 2016. A situação das áreas de endemismo da Amazônia com relação ao desmatamento e às áreas protegidas. Boletim de Geografia 34(3): 45-62. DOI: <http://dx.doi.org/10.4025/ bolgeogr.v34i3.30294>.

BUARQUE, D. C., F. M. FAN, A. R. PAZ \& W. COLLISCHONN, 2009. Comparação de métodos para definir direções de escoamento a partir de modelos digitais de elevação. Revista Brasileira de Recursos Hídricos 14(2): 91-103. DOI: <https://doi.org/10.21168/ rbrh.v14n2.p91-103>.

BURROUGH, P. A. \& R. A. MCDONNEL, 1998. Principles of geographical information systems: spatial information systems and geostatistics: 1-333. Oxford University Press, Oxford.

CÂMARA, G., R. C. M. SOUZA, U. M. FREITAS \& J. GARRIDO, 1996. Spring: integrating remote sensing and GIS by object-oriented data modelling. Computers \& Graphics 20(3): 395-403. DOI: $<$ https://doi.org/10.1016/0097-8493(96)00008-8>

CLARK LABS, 2018. TerrSet: geospatial monitoring and modeling system. Disponível em: <https://clarklabs.org/terrset/>. Acesso em: 4 março 2018. 
CONRAD, O., B. BECHTEL, M. BOCK, H. DIETRICH, E. FISCHER, L. GERLITZ, J. WEHBERG, V. WICHMANN \& J. BÖHNER, 2015. System for Automated Geoscientific Analyses (SAGA) v. 2.1.4. Geoscientific Model Development 8(7): 1991-2007.

DIRETORIA DE SERVIÇO GEOGRÁFICO (DSG), 2017. Banco de Dados Geográficos do Exército (BDGEx). Disponível em: $<$ http://www.geoportal.eb.mil.br/mediador/>. Acesso em: 30 dezembro 2017.

ENVIRONMENTAL SYSTEMS RESEARCH INSTITUTE (ESRI), 2010. What's new in ArcGIS 10: 1-177. ESRI, Redlands. Disponível em: <http://help.arcgis.com/en/arcgisdesktop/10.0/ pdf/whats_new_in_arcgis_10.pdf $>$. Acesso em: 4 março 2018.

ENVIRONMENTAL SYSTEMS RESEARCH INSTITUTE (ESRI), 2011. Arc Hydro geoprocessing tools - tutorial (Version 2.0): 1-251. ESRI, Redlands. Disponível em: <http://downloads.esri. com/archydro/archydro/Tutorial/Doc/Arc\%20Hydro\%20GP\%20 Tools\%202.0\%20-\%20Tutorial.pdf> . Acesso em: 5 março 2018.

ENVIRONMENTAL SYSTEMS RESEARCH INSTITUTE (ESRI), 2013. Overview of Arc Hydro terrain preprocessing workflows: 1-13. ESRI, Redlands. Disponível em: < http:// downloads.esri.com/archydro/archydro/Doc/Overview\%20 of\% 20 Arc $\% 20$ Hydro\%20terrain $\% 20$ preprocessing\%20 workflows.pdf>. Acesso em: 30 dezembro 2017.

ENVIRONMENTAL SYSTEMS RESEARCH INSTITUTE (ESRI), 2017a. How flow direction works. Disponível em: < http://pro. arcgis.com/en/pro-app/tool-reference/spatial-analyst/how-flowdirection-works.htm>. Acesso em: 8 março 2018.

ENVIRONMENTAL SYSTEMS RESEARCH INSTITUTE (ESRI), 2017b. How flow accumulation works. Disponível em: < http:// pro.arcgis.com/en/pro-app/tool-reference/spatial-analyst/howflow-accumulation-works.htm > . Acesso em: 8 março 2018.

FARR, T. G., P. A. ROSEN, C. EDWARD, R. CRIPPEN, R. DUREN, S. HENSLEY, M. KOBRICK, M. PALLER, E. RODRIGUEZ, L. ROTH, D. SEAL, S. SHAFFER, J. SHIMADA, J. UMLAND, M. WERNER, M. OSKIN, D. BURBANK \& D. ALSDORF, 2007. The Shuttle Radar Topography Mission. Reviews of Geophysics 45(2): 1-33. DOI: <https://doi.org/10.1029/2005RG000183>.

GOOGLE, 2018. Google Maps: rio purus passando pela cidade de Lábrea - AM. Disponível em: <https://www.google.com.br/ maps/@-7.2568285,-64.7983259,1011m/data=!3m1!1e3>. Acesso em: 10 março 2018.

GRASS DEVELOPMENT TEAM, 2018. GRASS GIS 7.4.1svn Reference Manual. Disponível em: <https://grass.osgeo.org/ grass74/manuals/index.html >. Acesso em: 4 março 2018.
HUANG, P. C. \& K. T. LEE, 2015. A simple depression-filling method for raster and irregular elevation datasets. Journal of Earth System Science 124(8): 1653-1665. DOI: <https://doi. org/10.1007/s12040-015-0641-2>.

INSTITUTO NACIONAL DE PESQUISAS ESPACIAIS (INPE), 2016. TerraHidro Wiki Page: TerraHidro 5 - Console applications. Disponível em: <http://www.dpi.inpe.br/terrahidro/doku.php>. Acesso em: 5 janeiro 2018.

INSTITUTO NACIONAL DE PESQUISAS ESPACIAIS (INPE), 2017. SPRING: Sistema de Processamento de Informações Georeferenciadas. DPI/INPE. Disponível em: <http://www.dpi. inpe.br/spring/portugues/index.html > . Acesso em: 27 dezembro 2017.

JENSON, S. K. \&J. O. DOMINGUE, 1988. Extracting topographic structure from digital elevation data for geographic information system analysis. Photogrammetric Engineering and Remote Sensing 54(11): 1593-1600.

JONES, R., 2002. Algorithms for using a DEM for mapping catchment areas of stream sediment samples. Computers \& Geosciences 28(9): 1051-1060. DOI: <https://doi.org/10.1016/ S0098-3004(02)00022-5>

LARSON, R. \& B. FARBER, 2015. Estatística aplicada: 6. ed.: 1-656. Pearson Education do Brasil, São Paulo.

MARK, D. M., 1984. Automated detection of drainage networks from digital elevation models. Cartographica 21(2-3): 168-178. DOI: <http://dx.doi.org/10.3138/10LM-4435-6310-251R>.

METZ, M., H. MITASOVA \& R. S. HARMON, 2011. Efficient extraction of drainage networks from massive, radar-based elevation models with least cost path search. Hydrology and Earth System Sciences 15(2): 667-678. DOI: <https://doi.org/10.5194/ hess-15-667-2011>.

MORAIS, R. C. S. \& M. C. L. SALES, 2016. Extração automática de drenagem: uma análise comparativa a partir de diferentes ferramentas e bases de dados. Revista Brasileira de Geografia Física 9(6): 1849-1860.

O'CALLAGHAN, J. F. \& D. M. MARK, 1984. The extraction of drainage networks from digital elevation data. Computer Vision, Graphics, and Image Processing 28(3): 323-344. DOI: <https:// doi.org/10.1016/S0734-189X(84)80011-0>.

OLIVEIRA, J. R. F., J. O. ORTIZ \& S. ROSIM, 2014. Comparison between drainage network extracted from elevation and surface models. Proceedings of the International Conference on Advanced Geographic Information Systems, Applications, and Services 6: 89-93.

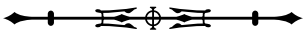


PACHECO, P., R. POCCARD-CHAPUIS \& J. C. EL HUSNY, 2017. Projeto TerraCert: territórios inovando para monitorar e comprovar progressos rumo à sustentabilidade: 1-4. CGIAR, Wageningen. Disponível em: <https://cgspace.cgiar.org/rest/bitstreams/93949/ retrieve >. Acesso em: 28 maio 2017.

PEREIRA, J. L. G., C. D. RENNÓ, O. T. SILVEIRA \& L. V. FERREIRA, 2012. Classificação da cobertura da terra na Amazônia com base em imagens de satélite e caracterização das classes com relação à superfície do terreno. Geografia 21(3): 115-131.

PEUCKER, T. K. \& D. H. DOUGLAS, 1975. Detection of surfacespecific points by local parallel processing of discrete terrain elevation data. Computer Graphics and Image Processing 4(4): 375-387. DOI: <https://doi.org/10.1016/0146-664X(75)90005-2>.

POGGIO, L. \& P. SOILLE, 2011. Influence of pit removal methods on river network position. Hydrological Processes 26(13): 19841990. DOI: <https://doi.org/10.1002/hyp.8290>.

QGIS DEVELOPMENT TEAM, 2018. QGIS user guide (Release 2.18): 1-473. Disponível em: <https://docs.qgis.org/2.18/pdf/ en/QGIS-2.18-UserGuide-en.pdf> . Acesso em: 4 março 2018.

QUINN, P., K. BEVEN, P. CHEVALLIER \& O. PLANCHON, 1991. The prediction of hillslope flow paths for distributed hydrological modelling using digital terrain models. Hydrological Processes 5(1): 59-79. DOI: <https://doi.org/10.1002/ hyp.3360050106>.

RENNÓ, C. D., 2009. Redução dos efeitos do desmatamento sobre modelo digital de elevação do SRTM usando imagem TM/ LANDSAT. Anais do Simpósio Brasileiro de Sensoriamento Remoto 14: 7095-7102.

RICCOMINI, C., P. C. F. GIANNINI \& F. MANCINI, 2000. Rios e processos aluviais. In: W. TEIXEIRA, M. C. M. TOLEDO, T. R. FAIRCHILD \& F. TAIOLI (Org.): Decifrando a Terra: 191-214. Oficina de Textos, São Paulo.

ROSIM, S., J. R. F. OLIVEIRA, A. C. JARDIM, L. M. NAMIKAWA \& C. D. RENNÓ, 2013. TerraHidro: a distributed hydrology modelling system with high quality drainage extraction. Proceedings of the International Conference on Advanced Geographic Information Systems, Applications, and Services 5: 161-167.

ROSIM, S., J. O. ORTIZ, M. Z. CUELLAR, J. R. F. OLIVEIRA \& A. C. JARDIM, 2014. Drainage network extraction of Brazilian semiarid region with potential flood indication areas. Proceedings of the Remote Sensing for Agriculture, Ecosystems, and Hydrology 16: 923919. DOI: <https://doi.org/10.1117/12.2066906>.
SEDGEWICK, R., 1992. Algorithms in C: 1-657. Addison-Wesley, Reading.

SEIBERT, J. \& B. L. MCGLYNN, 2007. A new triangular multiple flow direction algorithm for computing upslope areas from gridded digital elevation models. Water Resources Research 43(4): W04501. DOI: $<$ https://doi.org/10.1029/2006WR005128>.

SIQUEIRA, V. A., A. FLEISCHMANN, P. F. JARDIM, F. M. FAN \& W. COLLISCHONN, 2016. IPH-Hydro Tools: uma ferramenta open source para determinação de informações topológicas em bacias hidrográficas integrada a um ambiente SIG. Revista Brasileira de Recursos Hídricos 21(1): 274-287.

SOUZA, L. S. B. \& D. F. ROSSETTI, 2011. Caracterização da rede de drenagem na porção leste da ilha do Marajó e implicações tectônicas. Revista Brasileira de Geomorfologia 12(1): 69-83.

SOUZA, J. O. P. \& J. D. M. ALMEIDA, 2014. Modelo digital de elevação e extração automática de drenagem: dados, métodos e precisão para estudos hidrológicos e geomorfológicos. Boletim de Geografia 32(2): 134-149. DOI: <http://dx.doi.org/10.4025/ bolgeogr.v32i2.20470>.

SUGUIO, K. \& J. J. BIGARELLA, 1990. Ambientes fluviais: 2. ed.: 1-183. Editora da UFSC, Florianópolis.

SYSTAT SOFTWARE, 2009. SYSTAT 13: getting started: 1-388. Systat Software, San Jose. Disponível em: < http://biostats.unh.edu/ GettingStarted.pdf>. Acesso em: 7 março 2018.

TARBOTON, D. G., 1997. A new method for determination of flow directions and upslope areas in grid digital elevation models. Water Resources Research 33(2): 309-319. DOI: <https://doi. org/10.1029/96WR03137>.

TARBOTON, D. G., N. SAZIB \& P. DASH, 2015. TauDEM 5.3: quick start guide to using the TauDEM ArcGIS Toolbox: 1-39. Utah State University, Logan. Disponível em: <http://hydrology.usu.edu/ taudem/taudem5/TauDEM53GettingStartedGuide.pdf>. Acesso em: 4 março 2018.

UNITED STATES GEOLOGICAL SURVEY (USGS), 2018. EarthExplorer. Disponível em: <https://earthexplorer.usgs.gov/>. Acesso em: 7 março 2018.

WANG, L. \& H. LIU, 2006. An efficient method for identifying and filling surface depressions in digital elevation models for hydrologic analysis and modelling. International Journal of Geographical Information Science 20(2): 193-213. DOI: <https://doi. org/10.1080/13658810500433453>.

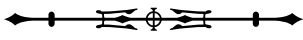


